\title{
Thrust Vector Control for Nuclear Thermal Rockets
}

\author{
Clinton B.F. Ensworth
}

Glenn Research Center, Cleveland, Ohio 


\section{NASA STI Program . . . in Profile}

Since its founding, NASA has been dedicated to the advancement of aeronautics and space science. The NASA Scientific and Technical Information (STI) program plays a key part in helping NASA maintain this important role.

The NASA STI Program operates under the auspices of the Agency Chief Information Officer. It collects, organizes, provides for archiving, and disseminates NASA's STI. The NASA STI program provides access to the NASA Aeronautics and Space Database and its public interface, the NASA Technical Reports Server, thus providing one of the largest collections of aeronautical and space science STI in the world. Results are published in both non-NASA channels and by NASA in the NASA STI Report Series, which includes the following report types:

- TECHNICAL PUBLICATION. Reports of completed research or a major significant phase of research that present the results of NASA programs and include extensive data or theoretical analysis. Includes compilations of significant scientific and technical data and information deemed to be of continuing reference value. NASA counterpart of peer-reviewed formal professional papers but has less stringent limitations on manuscript length and extent of graphic presentations.

- TECHNICAL MEMORANDUM. Scientific and technical findings that are preliminary or of specialized interest, e.g., quick release reports, working papers, and bibliographies that contain minimal annotation. Does not contain extensive analysis.

- CONTRACTOR REPORT. Scientific and technical findings by NASA-sponsored contractors and grantees.
- CONFERENCE PUBLICATION. Collected papers from scientific and technical conferences, symposia, seminars, or other meetings sponsored or cosponsored by NASA.

- SPECIAL PUBLICATION. Scientific, technical, or historical information from NASA programs, projects, and missions, often concerned with subjects having substantial public interest.

- TECHNICAL TRANSLATION. Englishlanguage translations of foreign scientific and technical material pertinent to NASA's mission.

Specialized services also include creating custom thesauri, building customized databases, organizing and publishing research results.

For more information about the NASA STI program, see the following:

- Access the NASA STI program home page at http://www.sti.nasa.gov

- E-mail your question to help@sti.nasa.gov

- Fax your question to the NASA STI Information Desk at 443-757-5803

- Phone the NASA STI Information Desk at 443-757-5802

- Write to: STI Information Desk NASA Center for AeroSpace Information 7115 Standard Drive Hanover, MD 21076-1320 


\section{Thrust Vector Control for Nuclear Thermal Rockets}

Clinton B.F. Ensworth

Glenn Research Center, Cleveland, Ohio

Prepared for the

49th Joint Propulsion Conference and Exhibit

cosponsored by AIAA, ASME, SAE, and ASEE

San Jose, California, July 14-17, 2013

National Aeronautics and

Space Administration

Glenn Research Center

Cleveland, Ohio 44135 


\section{Acknowledgments}

The author would like to thank Stanley Borowski and John Taylor, NASA Glenn Research Center, Dave McCurdy, Vantage Partners LLC, and Mike Houts, NASA Marshall Space Flight Center for their encouragement and interest in this work, as well as, Chris Moore and John Warren, NASA Headquarters for their continued support of the Nuclear Cryogenic Propulsion Stage (NCPS) project through NASA’s Advanced Exploration Systems (AES) program.

This report contains preliminary findings, subject to revision as analysis proceeds.

Trade names and trademarks are used in this report for identification only. Their usage does not constitute an official endorsement, either expressed or implied, by the National Aeronautics and Space Administration.

Level of Review: This material has been technically reviewed by technical management.

Available from

NASA Center for Aerospace Information 7115 Standard Drive

Hanover, MD 21076-1320
National Technical Information Service 5301 Shawnee Road Alexandria, VA 22312

Available electronically at http://www.sti.nasa.gov 


\title{
Thrust Vector Control for Nuclear Thermal Rockets
}

\author{
Clinton B.F. Ensworth \\ National Aeronautics and Space Administration \\ Glenn Research Center \\ Cleveland, Ohio 44135
}

\begin{abstract}
Future space missions may use Nuclear Thermal Rocket (NTR) stages for human and cargo missions to Mars and other destinations. The vehicles are likely to require engine thrust vector control (TVC) to maintain desired flight trajectories. This paper explores requirements and concepts for TVC systems for representative NTR missions. Requirements for TVC systems were derived using 6 degree-of-freedom models of NTR vehicles. Various flight scenarios were evaluated to determine vehicle attitude control needs and to determine the applicability of TVC. Outputs from the models yielded key characteristics including engine gimbal angles, gimbal rates and gimbal actuator power. Additional factors such as engine thrust variability and engine thrust alignment errors were examined for impacts to gimbal requirements. Various technologies are surveyed for TVC systems for the NTR applications. A key factor in technology selection is the unique radiation environment present in NTR stages. Other considerations including mission duration and thermal environments influence the selection of optimal TVC technologies. Candidate technologies are compared to see which technologies, or combinations of technologies best fit the requirements for selected NTR missions. Representative TVC systems are proposed and key properties such as mass and power requirements are defined. The outputs from this effort can be used to refine NTR system sizing models, providing higher fidelity definition for TVC systems for future studies.
\end{abstract}

\section{Nomenclature}

$\begin{array}{ll}\text { ASV } & \text { Asteroid Survey Vehicle } \\ \text { CG } & \text { Center of Gravity } \\ \text { GRC } & \text { Glenn Research Center } \\ \text { kN } & 1000 \text { Newtons } \\ \text { klbf } & 1000 \text { pounds of force, thrust } \\ \text { LH }_{2} & \text { Liquid Hydrogen, propellant } \\ \text { MTV } & \text { Mars Transfer Vehicle } \\ \text { NEA } & \text { Near Earth Asteroid } \\ \text { NERVA } & \text { Nuclear Engine for Rocket Vehicle Application } \\ \text { Nm } & \text { Newton meter } \\ \text { NTR } & \text { Nuclear Thermal Rocket } \\ \text { RCS } & \text { Reaction Control System } \\ \mathrm{t} & \text { metric ton }(1 \mathrm{t}=1000 \mathrm{~kg}) \\ \text { TVC } & \text { Thrust Vector Control } \\ \text { TVT } & \text { Thrust Vector Trim }\end{array}$




\subsection{Introduction}

Nuclear Thermal Rockets have been considered for space missions for more than 55 years. These mission concepts have capitalized on the high specific impulse capability of NTR engines, up to $900 \mathrm{sec}$ or more, resulting in increased payload or faster trip times compared to other propulsion technologies.

Recent studies have looked at NTR technology for a variety of missions including lunar, near Earth asteroids (NEA) and Mars targets (Ref. 1). Most of these missions use elements that are assembled in low Earth orbit (LEO) to create one or more large vehicles to carry out the mission. Assembled vehicles may be $400 \mathrm{t}$ or more with lengths of over $100 \mathrm{~m}$. Multiple, smaller sized engines ( 15 to $25 \mathrm{klbf}$ thrust, 66.7 to $111 \mathrm{kN}$ ) are used on a vehicle to enable the mission to continue with the loss of an engine. The engine design is based on the ROVER program's $25 \mathrm{klbf}$ Pewee engine (Refs. 2 and 3). Loss of a larger engine on a single engine vehicle would almost certainly result in loss of the mission. The smaller engine is also more economical to build and test. Liquid hydrogen $\left(\mathrm{LH}_{2}\right)$ is used as the propellant for these cases.

\subsection{Vehicle Attitude Control}

Control of these large vehicles during powered flight is expected to use some means of thrust vector control, TVC. Thrust vector control allows the alignment of the vehicle thrust with vehicle center of gravity (CG) to maintain straight line flight or to induce vehicle steering as desired. The objective of this paper is to define the requirements and conceptual design of thrust vector control systems for NTR applications. Several different vehicles will be examined to explore vehicle and mission influences on TVC design.

A reaction control system (RCS) can also manage vehicle attitude, and is essential during times when engines are not thrusting. While the NTR engines are thrusting, the use of thrust vector control can avoid most use of RCS propellant. Otherwise, RCS propellant consumption could become excessive in some cases, especially off-nominal situations such as thrust asymmetry due to engine malfunction. In a multiengine vehicle, differential engine thrusting could be used to steer the vehicle, as an alternative to TVC. But this method would not work if one of three engines failed. Definition of the capabilities of a TVC system also helps define the requirements of the RCS.

Gimbaling of engines is the most common method of thrust vector control for large rockets. Typical configurations includes a gimbal bearing attached to the engine that allows two axis rotation of the engine (e.g., yaw and pitch rotation) but prevents rotation about the axis of the engine. The gimbal bearing carries most of the engine thrust load. Two actuators, attached to the engine and vehicle structure can be mounted $90^{\circ}$ apart to provide full two-axis gimbaling. Instead of a gimbal bearing on the engine axis, gimbal motion can be achieved by the use of a gimbal ring that is external to the engine, as in a gyroscope mount. One gimbal actuator would be attached to the ring, the other attaches to the engine, $90^{\circ}$ apart.

An alternative method of engine steering was considered during the Nuclear Engine for Rocket Vehicle Application (NERVA) program (Ref. 4). This method, designated Thrust Vector Trim (TVT) uses one engine attach point with a fixed ball and socket joint and two moveable engine attach points that translate parallel to the rocket engine axis. The fixed and moveable points are located $120^{\circ}$ around the engine axis. By actuating the moveable points fore and aft, the engine thrust axis can be directed within a cone of operation. The advantage of this configuration is the elimination of the engine gimbal bearing; there is only the need for a flexible connection to carry propellant into the engine. The disadvantage of this configuration is that the mechanisms that provide the engine movement must each continuously carry about one third of the engine thrust load. The engine attach points must similarly be designed to react the same thrust loads. This method may be attractive for relatively low thrust engines. Mechanical engine steering concepts are shown in Figure 1.

Other thrust vector control methods include the use of paddles or vanes to alter the rocket engine exhaust to direct the net thrust vector. These methods are problematic because the thrust directing elements must withstand the high temperatures in the rocket exhaust. 


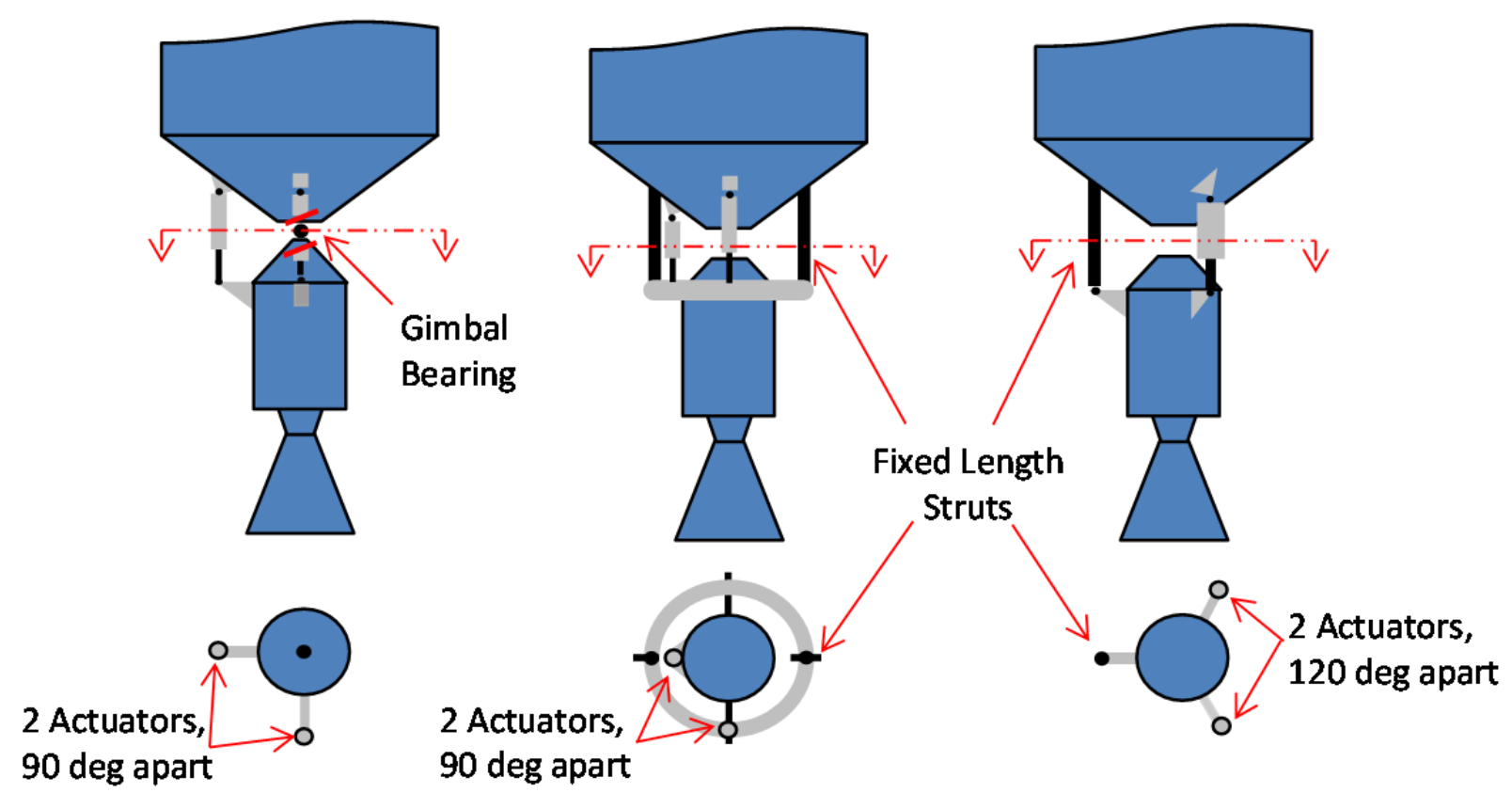

\section{Gimbal Bearing}

\section{Gimbal Ring}

Thrust Vector Trim

Figure 1.-Mechanical engine steering.

Engine thrust vectoring can also be achieved by control of auxiliary paths of propellant exhaust alongside the main thrust or by fluid injection into the rocket nozzle to affect the net thrust. In general, these techniques are less efficient than mechanical engine steering. For the purpose of these studies, use of a conventional gimbal bearing and engine gimbaling is assumed. As in the NERVA concepts, it will be assumed that the entire engine assembly, including turbopumps, reactor, and nozzle will be gimbaled as a unit at the engine-vehicle interface.

The thrust vector control requirements of any rocket are dependent on the configuration and the mission of the rocket. For nuclear thermal rockets currently under consideration, the operation of the rocket engine occurs only in space (conventional rocket engine boosters are used to reach Earth orbit). This eliminates the need to consider ascent through the atmosphere, which is usually the most demanding phase for the thrust vector control function.

Table 1 lists events during an NTR mission that require control of vehicle attitude. The table indicates whether thrust vector control or a reaction control system is suitable to provide the necessary control. In all of the cases where RCS is not indicated, it is because these are long term events that would likely require excessive propellant.

The effects listed in Table 1 are discussed below. As noted, some effects only apply to multi-engine vehicles. In the ideal case, all the vehicle thrust (one or more engines) is axisymmetric and parallel to the vehicle longitudinal axis (x-axis) and the vehicle CG is located on the longitudinal axis. In this situation, for straight line flight, no control is required. The following cases describe deviations from this ideal. Figure 2 shows the coordinate system used in this report with definition of vehicle pitch, yaw, and roll rotations. Nominal thrusting is in the vehicle $+\mathrm{X}$ direction. Also shown are notional engine locations for a three engine cluster with engine gimbal axis definitions. 
TABLE 1.-APPLICABILITY OF TVC OR RCS TO PROVIDE CONTROL TO THE VEHICLE

\begin{tabular}{|l|c|c|}
\hline \multicolumn{1}{|c|}{ Scenario } & TVC & RCS \\
\hline 2.1 Engine Thrust Asymmetry & --- & Yes \\
\hline 2.1.1 Start Transient & Yes & Not likely \\
\hline 2.1.2 Nominal Operation & Yes & Yes \\
\hline 2.1.3 Shutdown Transient & Not likely & Yes \\
\hline 2.1.4 Cool Down Operation & Possibly & No \\
\hline 2.1.5 Off-nominal with 1 of x engines out & Yes & Yes \\
\hline 2.1.6 Off-nominal TVC gimbal failure & Yes & Yes \\
\hline 2.2 Steering Maneuver (Pitch \& Yaw) & Yes & Not likely \\
\hline 2.3 Roll Maneuver & Possibly & Not likely \\
\hline 2.4 Vehicle CG offset, nominal & Yes & Not likely \\
\hline 2.5 Engine Mounting Misalignments & Yes & Yes \\
\hline 2.6 Unplanned CG shift & Yes & Yes \\
\hline 2.7 Damping Slosh Disturbance & Not likely & Yes \\
\hline 2.8 Coast Phase Rendezvous and Docking & No & No \\
\hline 2.9 Coast Phase Attitude Maneuvers & & \\
\hline
\end{tabular}

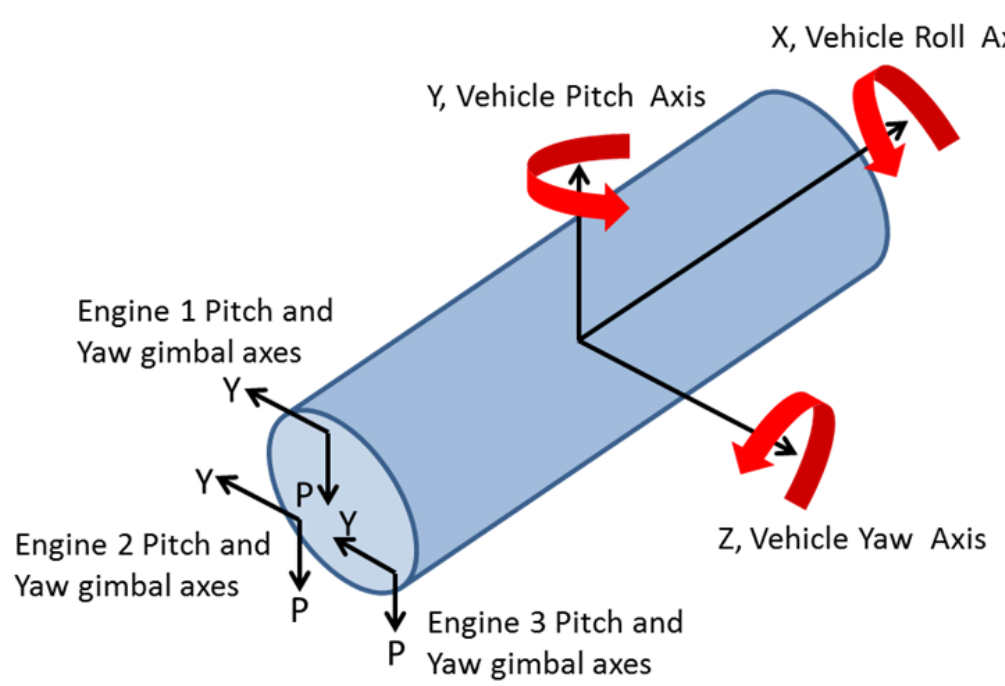

Figure 2.-Vehicle coordinates and engine gimbal definitions.

\subsection{Engine Thrust Asymmetry}

\subsubsection{Engine Start Transient}

The startup transient time of an NTR engine is longer than a typical chemical engine. The NTR engine has temperature and pressure ramp rate limits that result in a thrust buildup period of a half minute or more. During the start transient it is likely that the thrust levels will not rise simultaneously in all engines of a multi-engine vehicle. (An individual engine also undoubtedly has asymmetric thrust transients relative to its centerline during start-up, but the effects are likely to be negligible for this study.)

\subsubsection{Nominal Operations}

The net thrust from any rocket engine nozzle has some level of offsets and misalignments with respect to the engine reference centerline (Fig. 3). Some of these effects are static and can be quantified through testing and analysis. Other variances change during the operation of the engine due to thermal and loading effects and may be difficult to predict. Engine specifications typically define maximum allowable thrust offset and thrust misalignment. From a multi-engine vehicle perspective, thrust asymmetry can be due to unintended differences in net thrust among the engines. For an NTR engine, thrust is a function of propellant flow rate and temperature. Each of these variables has a tolerance for controllability, which should also be in engine specifications. 


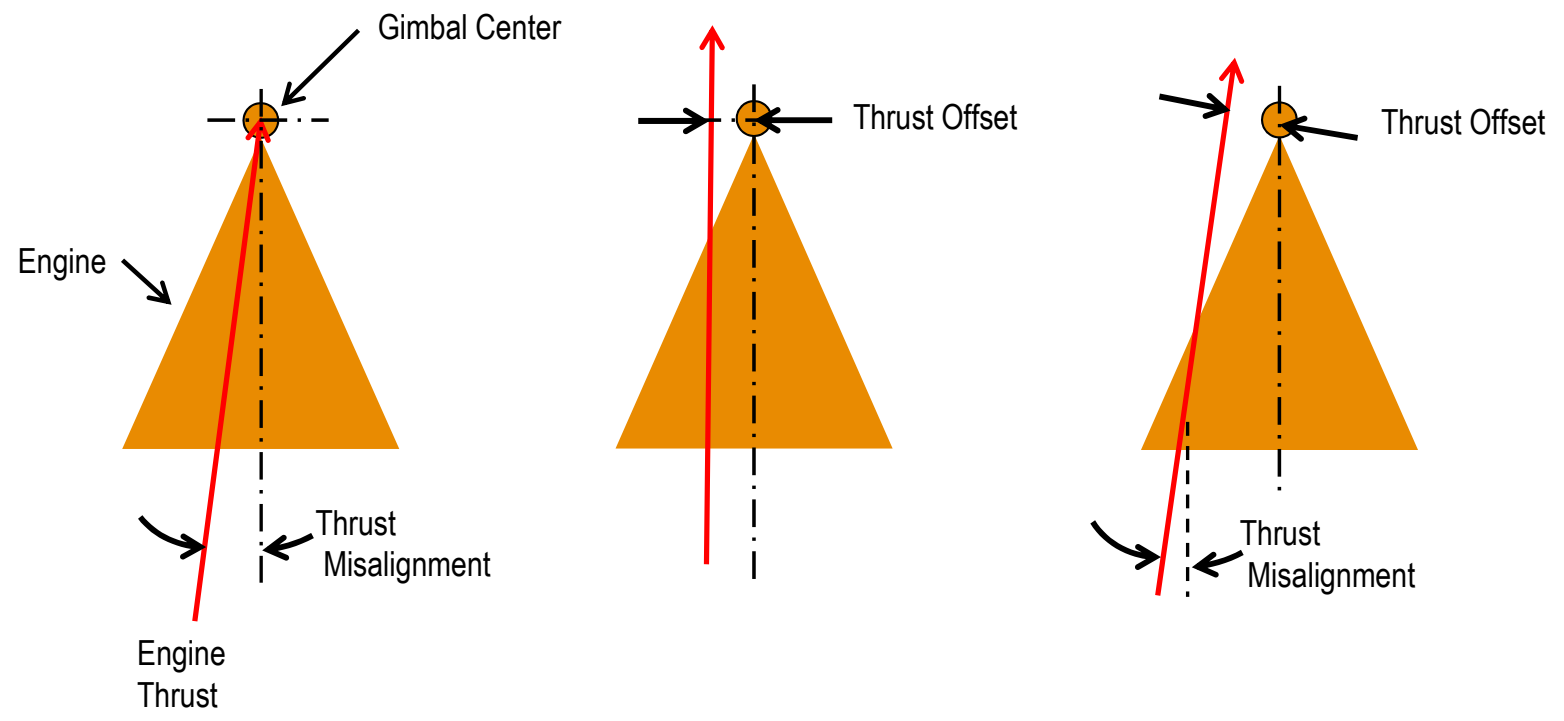

Figure 3.-Engine thrust deviations: misalignment, thrust offset and combined deviations.

\subsubsection{Engine Shutdown Transient}

As with the start transient, the shutdown transient in a multi-engine vehicle will likely not occur simultaneously. The shutdown scenario is different from startup, however because as the thrust levels decrease, there is decreasing control authority from TVC. The shutdown procedure involves multiple steps including a throttling period, throttle hold, temperature retreat by use of reactor control drums, and $\mathrm{LH}_{2}$ pump tail off as thrust decreases from 100 percent. Residual vehicle attitude rates at shutdown may call for the use of RCS for attitude rate correction.

\subsubsection{Engine Cool Down Operation}

After each engine firing and reactor shutdown, there is a period of time required to cool the reactor using the propellant. The cool down period starts when the turbopump is off and propellant is fed by tank pressure, controlled by the propellant supply valve. Hydrogen flow is reduced to low values during this period, but some useful thrust is produced. The low thrust may not be sufficient to allow for thrust vectoring to control the vehicle attitude during these times. RCS may be required to control the vehicle.

\subsubsection{Off-Nominal, Engine Failure}

In a multi-engine vehicle, this case represents an extreme example of thrust asymmetry. The use of RCS alone to control the vehicle after loss of an engine would require a high rate of RCS propellant usage. If loss of an engine is assumed to be a credible event, then engine thrust vectoring most likely is required for this scenario.

\subsubsection{Off-Nominal, TVC Failure}

In a multi-engine vehicle we can look at the effect of a failure within the thrust vector control system. Various types of failure are conceivable. Typical TVC failure cases include failure at null engine position and failure at maximum engine rotation. Failure in the maximum rotation, or "hard over" case, is a consideration for keeping the physical engine rotation range as small as necessary. For the TVC failure cases it is desirable that the remaining engines have sufficient control authority to enable the mission to continue. 


\subsection{Steering Maneuver (Pitch and Yaw)}

During engine thrusting, TVC can be used to steer the vehicle along the desired trajectory. The maneuver is initiated by thrust vector action that rotates the vehicle about the pitch and yaw axes, followed by a thrust vector action that stops the vehicle rotation at the desired attitude, for the new vehicle heading. This maneuver could also be performed by RCS.

\subsection{Roll Maneuver}

Clustered engines in a multi-engine vehicle could provide a roll torque on the vehicle if engines were capable of being angled to do so. Vehicle rotation from main engine torque would require unique commanding (different yaw and pitch gimbal commands) to each engine, a feature that is otherwise not required. Roll capability would be lost however, if 1 of 2 or 1 of 3 engines was lost. For this study, vehicle roll capability is provided by RCS.

\subsection{Vehicle CG Offset}

Ideally, the vehicle CG would remain on the vehicle longitudinal axis (x axis) throughout the mission. The center of gravity will move along the longitudinal axis as propellants are consumed. Static CG offsets in $y$ and $\mathrm{z}$ will occur because everything within and on the vehicle is not perfectly symmetric, especially as elements are added or jettisoned from the vehicle. Dynamic CG offsets will occur as the vehicle flexes and propellants slosh.

Unless the static misalignment is corrected by the TVC system, there will be a constant torque on the vehicle when engines are thrusting. It would be costly in propellant to use RCS to counteract this torque for all but the smallest torques.

\subsection{Engine Mounting Misalignment}

Engine mounting misalignment is a deviation from the ideal alignment. Deviations include lateral misalignments in $\mathrm{y}$ and $\mathrm{z}$ direction (deviations in $\mathrm{x}$ location, the nominal thrust direction, are less important). Deviations also include angular misalignments of the engine mounting locations and include engine gimbal actuator length deviations that cause unwanted bias rotations of an engine.

\subsection{Off-Nominal, Unplanned CG Shift}

This scenario may include an instance where a planned deployment or a planned jettison event does not occur properly, leaving the vehicle with a center of gravity point that is outside of the nominal CG box. Depending on the magnitude of the CG offset, TVC may be able to compensate for the unplanned event and may allow completion of the mission.

\subsection{Off-Nominal, Damping of Propellant Slosh}

Propellants within the propellant tanks may be excited by some event such as an attitude maneuver and may begin sloshing. Sloshing frequency is dependent on tank geometry and fill level, propellant density and vehicle acceleration. Sloshing can be detrimental to the vehicle if the moving propellants cause vehicle attitude to be affected, or if vehicle RCS or TVC control inadvertently reinforces the sloshing due to undesireable feedback. Damping can be incorporated in the tank design to suppress sloshing, though this adds extra mass. Extreme sloshing could potentially be dampened by use of RCS firings. Damping of propellant slosh by TVC may be possible if engine movements could be timed to counteract slosh effects. 


\subsection{Coast Phase Rendezvous, Docking and Separation of Stages}

During the assembly of the vehicle in low Earth orbit and during various separation events, RCS will be needed to perform rendezvous and attitude control maneuvers.

\subsection{Nominal-During Coast, Vehicle Attitude Change}

During coast periods when engines are not firing, RCS will be needed to perform vehicle attitude maneuvers including pitch, yaw, and roll rotations for vehicle communications, thermal, power or other considerations.

\subsubsection{Combining Effects for Analysis Purposes}

Some of the effects requiring control action can be combined in analysis because they act in a similar manner. For example, a displacement of vehicle $C G$ of $1 \mathrm{~cm}$ in the plus y direction and an error of engine mounting location by $1 \mathrm{~cm}$ in the negative y direction have the same effect on the vehicle. Both displacements tend to cause the vehicle to rotate about the $\mathrm{z}$ axis when the engine is firing.

Thrust offset within an individual engine also acts the same as an engine mount displacement or a vehicle CG displacement. An additional consideration for engine thrust offset is that it directly affects TVC actuation loads, because the offset creates a moment about the engine mounting point that must be resisted by the actuator.

For a multi-engine cluster, engine thrust offsets and engine mounting displacements must be combined for all engines to determine the net thrust effect on the vehicle.

These individual offset and displacement deviations cannot be quantified until the vehicle and engine designs are very mature. For this study, the effects of engine mounting deviations, vehicle CG, engine thrust offset will be examined at the combined level.

The net effect of these linear offsets from ideal is a moment on the vehicle that can be counteracted by rotation of the engines to put the net thrust through the vehicle center of gravity. The amount of engine rotation is based on the simple geometry of the effective thrust application point and the vehicle center of gravity. Similarly, net engine thrust asymmetry due to engine-to-engine variation contributes to a moment on the vehicle that can be counteracted by rotating the engines.

Individual engine thrust angular alignment and engine mounting angular alignment effects can also be combined. The effects cause the engine thrust to be non-parallel with the vehicle centerline. For an individual engine, the correction is simply an engine rotation to counteract the misalignment. For multiple engines, a uniform angular correction can be applied to all engines that makes the net thrust as parallel as possible. Uniform corrections eliminate the need to determine the alignment errors for the individual engine axes. If biases are determined before flight for individual engine pitch and yaw axes they could be added to the uniform commands. This would improve thrust efficiency by making the thrust of each engine more parallel with the other engines.

It is possible that engine alignment errors may combine in a manner to produce a roll torque on the vehicle. As noted, TVC cannot produce counteracting roll torques, unless the engines receive individual commands.

All of these effects are near steady state and impact engine rotation range (gimbal range) only, not TVC dynamic performance.

The vehicle attitude controller does not need to know information about any of the deviations and misalignment to control the vehicle. The effects produce torques on the vehicle and the controller tries to counteract them with thrust vector control commands. 


\subsection{Study Approach}

For initial study purposes, two representative NTR vehicle concepts were considered. These vehicles were similar to ones described in Reference 1 and were developed by the same team at the NASA Glenn Research Center (GRC). A Mars Transfer Vehicle (MTV) designed for a 600 day Mars orbital mission (with a 60 day stay time at Mars) is shown in Figure 4. This vehicle represents one of the largest vehicles currently being considered using 3-25 kbf thrust engines. This combination yields a relatively low initial thrust to weight ratio that may have impacts on TVC design.

The piloted Mars vehicle includes four $\mathrm{LH}_{2}$ tanks. The tank at the aft end is the core propulsion stage tank. The next tank is called an in-line tank. The final two tanks are called drop tanks because after the propellants are depleted, this tank set can be jettisoned, reducing vehicle mass.

For this mission, the NTR engines operate for the following mission phases:

1. Engine firings from low Earth orbit to escape on a trajectory to Mars (two perigee burns)

2. Engine firing for Mars orbit capture

3. Engine firing to send crew toward Earth

The two drop tanks are jettisoned after the first perigee burn. Immediately after the first burn the engines will be in cool-down mode, so it may be interesting to examine this case, with a still relatively heavy vehicle with very low thrust.

The other vehicle used in this study was designed for a 344 day mission to the NEA, Apophis. The crewed asteroid survey vehicle (ASV) is shown in Figure 5. It includes only two $\mathrm{LH}_{2}$ tanks, a core stage tank and a drop tank. The vehicle had 3-25 klbf engines. The engines are identical for both vehicles. As with the Mars vehicle, there are a total of four engine firings; two to escape Earth orbit, one for target capture and one for return to Earth. The vehicle at the end of this last burn will be relatively light and with the thrust of three engines it represents an NTR case with a high thrust to weight ratio.

Table 2 shows key information for cases in this study including total vehicle mass and mass moment of inertia properties for each of the two vehicles at two different points in the two missions, as indicated. The mass values are from the detailed mass estimates that were produced by the GRC team for each of the configurations. The moments of inertia are approximate based on preliminary estimates of mass distributions.

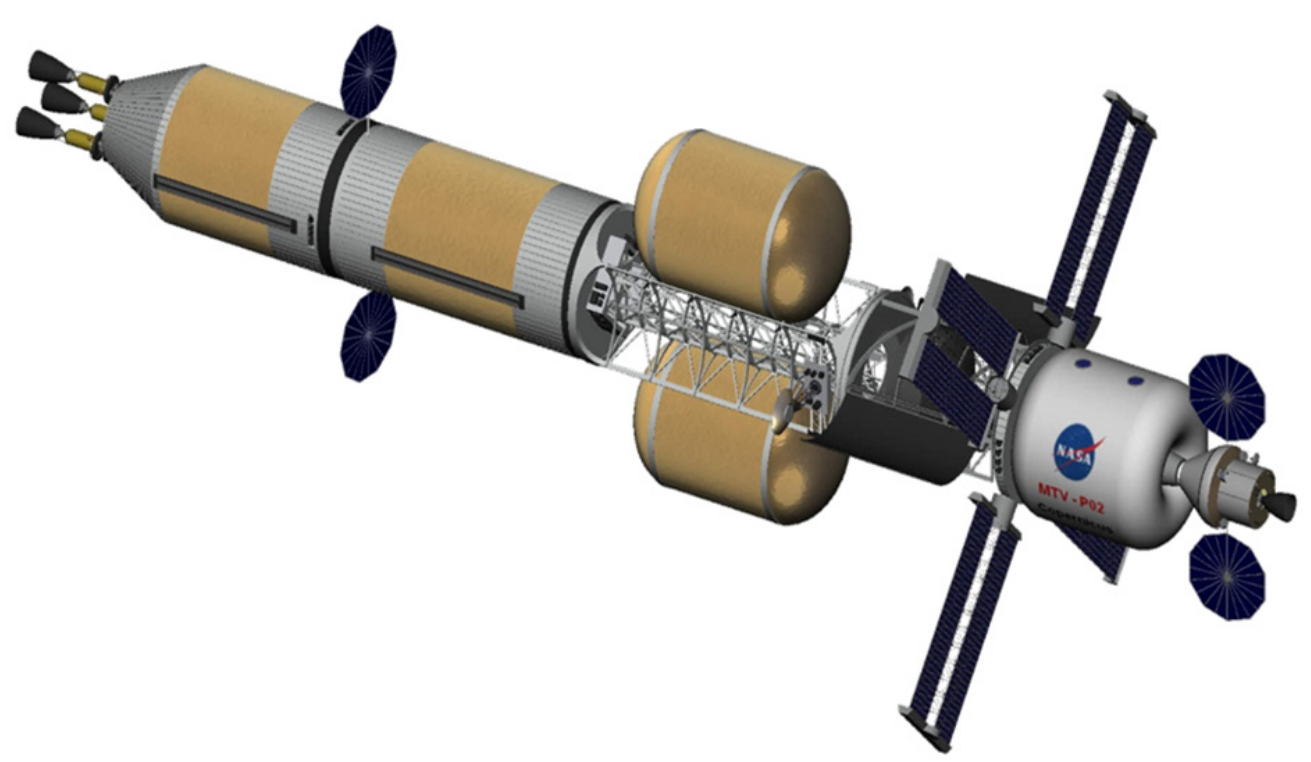

Figure 4.-Crewed vehicle for 600 day Mars obital mission. 


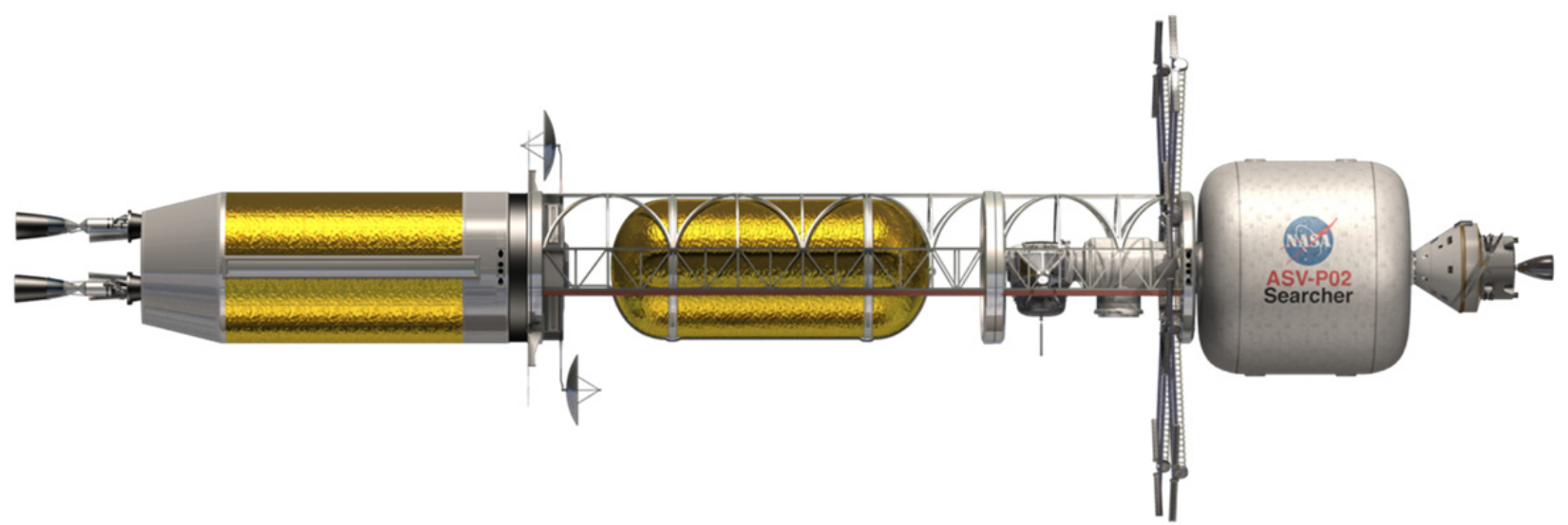

Figure 5.-Crewed ASV for 344-day Apophis NEA mission.

TABLE 2.-VEHICLE PROPERTIES FOR STUDY

\begin{tabular}{|c|c|c|c|c|c|c|c|c|}
\hline \multirow[t]{2}{*}{ Mission } & \multirow[t]{2}{*}{$\begin{array}{l}\text { Vehicle case } \\
\text { designation }\end{array}$} & \multirow[t]{2}{*}{ Phase } & \multirow{2}{*}{$\begin{array}{l}\text { Vehicle } \\
\text { mass, } \\
\text { including } \\
\text { engines, } \\
\text { kg }\end{array}$} & \multicolumn{3}{|c|}{$\begin{array}{l}\text { Vehicle mass moment of inertia, not } \\
\text { including engines }\end{array}$} & \multirow[t]{2}{*}{$\begin{array}{l}\text { No. of } \\
\text { engines }\end{array}$} & \multirow{2}{*}{$\begin{array}{c}\text { Thrust } \\
\text { per } \\
\text { engine, } \\
\text { kN }\end{array}$} \\
\hline & & & & $\begin{array}{l}\text { Ixx, } \\
\text { kg-m }\end{array}$ & $\begin{array}{c}\text { Iyy, } \\
\text { kg-m² }\end{array}$ & $\begin{array}{c}\mathrm{Izz}, \\
\mathrm{kg}-\mathrm{m}^{2}\end{array}$ & & \\
\hline \multirow[t]{2}{*}{$\begin{array}{l}600 \text { day Mars } \\
\text { mission }\end{array}$} & Mars 1 & $\begin{array}{l}\text { Start of } 1 \mathrm{st} \\
\text { perigee } \\
\text { burn }\end{array}$ & 423,667 & $7.076 \mathrm{e} 6$ & $2.072 \mathrm{e} 8$ & $2.105 \mathrm{e} 8$ & 3 & 111 \\
\hline & Mars 2 & $\begin{array}{l}\text { End of } 1 s t \\
\text { perigee } \\
\text { burn }\end{array}$ & 302,495 & $2.858 \mathrm{e} 6$ & $2.000 \mathrm{e} 8$ & $2.007 \mathrm{e} 8$ & 3 & 111 \\
\hline \multirow[t]{2}{*}{$\begin{array}{l}344 \text { day } \\
\text { Apophis NEA } \\
\text { mission }\end{array}$} & Apophis 1 & $\begin{array}{l}\text { Start of } 1 \mathrm{st} \\
\text { perigee } \\
\text { burn }\end{array}$ & 210,600 & $1.576 \mathrm{e} 6$ & $7.879 \mathrm{e} 7$ & $7.879 \mathrm{e} 7$ & 3 & 111 \\
\hline & Apophis 2 & $\begin{array}{l}\text { End of } \\
\text { trans Earth } \\
\text { burn }\end{array}$ & 88,227 & $1.142 \mathrm{e} 6$ & $5.709 \mathrm{e} 7$ & $5.709 \mathrm{e} 7$ & 3 & 111 \\
\hline
\end{tabular}

\subsection{Model Description}

A simulation model was created to explore TVC requirements for NTR missions. The model was created using Mathworks SimMechanics application that is an extension to Simulink. The SimMechanics application permits dynamic simulation of multiple connected bodies in three-dimensional space. The current model assumes all bodies are rigid; various techniques are possible to simulate flexible effects. The basic model includes one mass to represent the vehicle body and one mass for each of the three engines. The vehicle mass has full 6 degrees-of-freedom. Also included in the model are two-axis gimbal joints between the engines and vehicle masses and the actuators to move the gimbals. Interactions between masses is fully represented including the tail-wags-dog effect.

Inputs to the model include vehicle and engine mass properties and geometry. Inputs for simulation include time histories of engine thrust and commanded vehicle attitude for three axes. The basic model is shown in Figure 6.

The vehicle model has simple pitch and yaw attitude controllers based on proportional and derivative control of vehicle attitude. Integral control can be turned on to reduce steady state error if desired. The attitude controllers produce commanded yaw and pitch angles for the engine actuator controllers which operate on an inner control loop based on gimbal position feedback. No attempt was made to optimize control parameters which were manually determined to provide reasonable performance for nominal operations. 


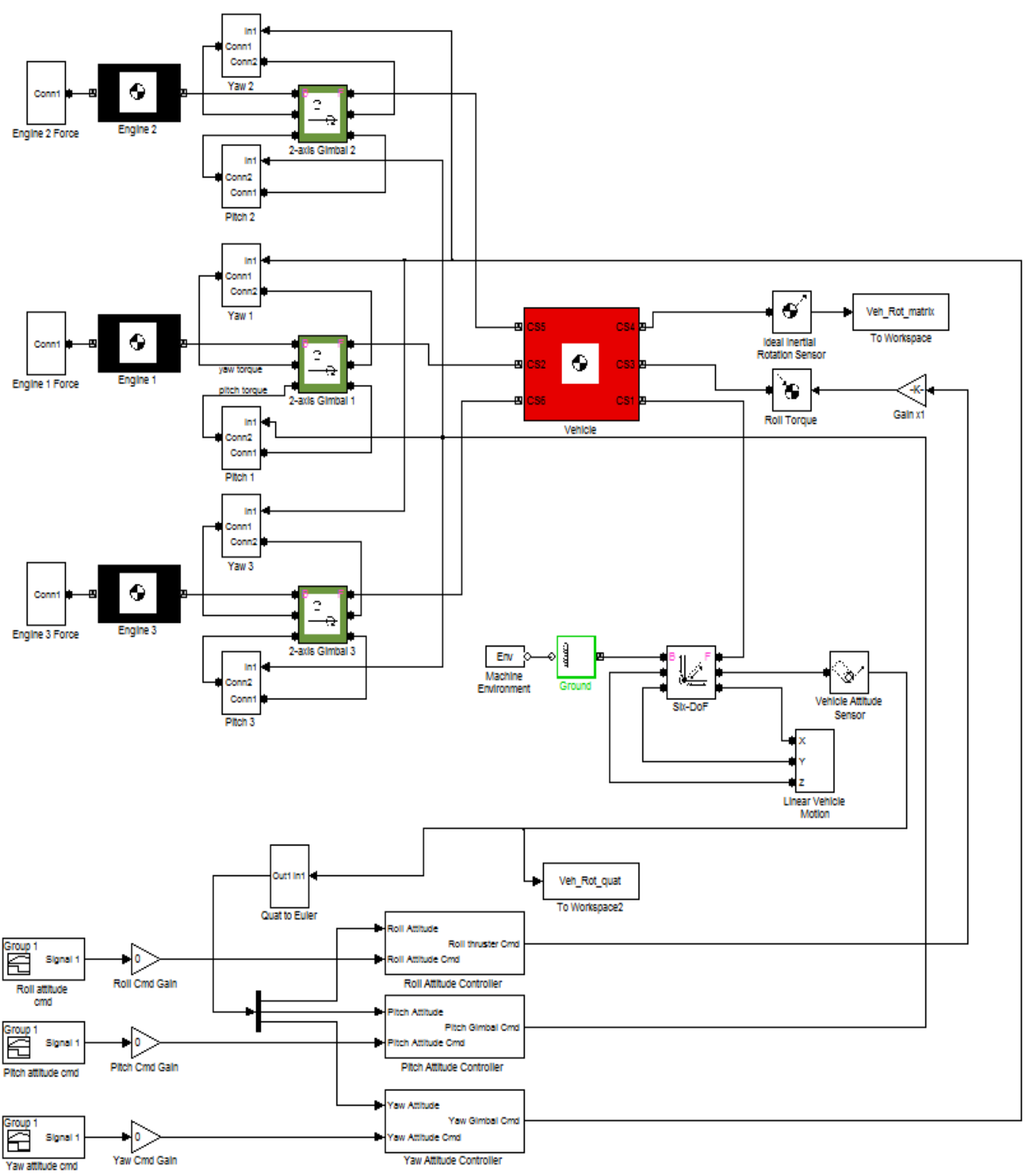

Figure 6.-SimMechanics model for 3 engine NTR vehicle.

Key outputs of the simulations are the resultant engine gimbal angles and rates and actuator torques. The gimbal actuator is an ideal actuator (i.e., no actuator dynamics or non-linear effects) and acts as a gimbal torque provider. In application the actuator is more likely to be a linear force provider acting with a torque arm, producing a gimbal torque.

The torque required to gimbal an engine is dependent on several factors including engine inertial load, engine CG offset, engine thrust offset, propellant duct spring loads and gimbal friction. A gimbal torque limit was included in the model to represent the reality that physical hardware cannot provide unlimited torque. All these factors and limits are included in the model and can be varied as desired. The gimbal commands output by the attitude controllers were also limited, though they were set high enough that they rarely were in effect, since a key objective of the study was to see how large gimbal angles needed to be to fly various scenarios. 


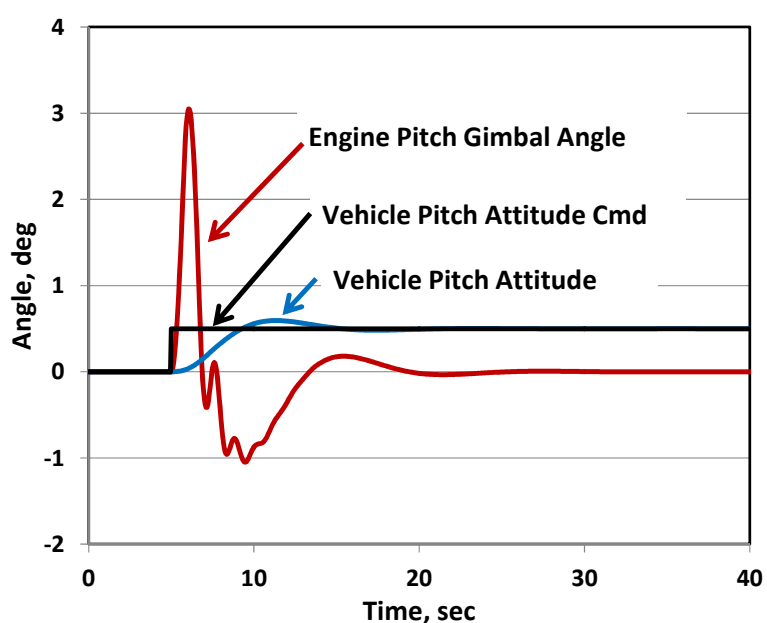

Figure 7.-Mars 1 vehicle response to a $0.5^{\circ}$ step attitude command.

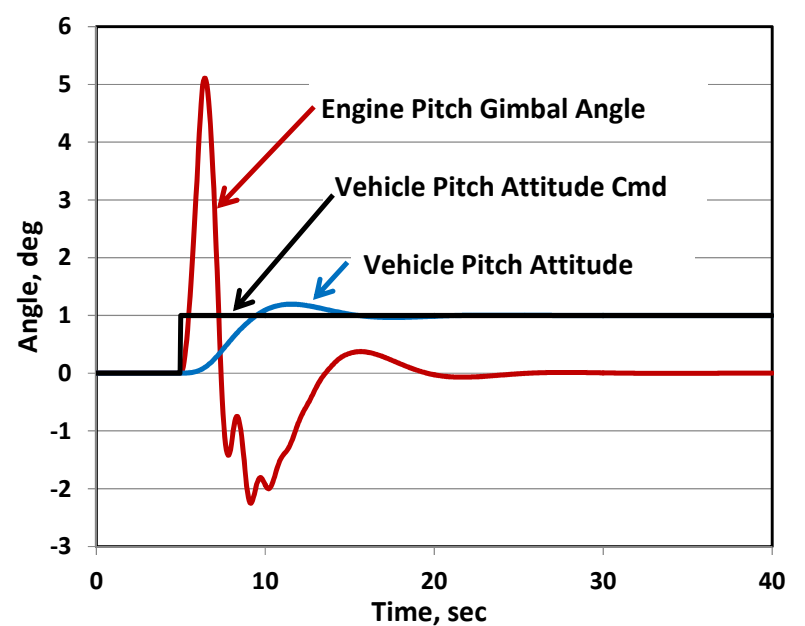

Figure 8.-Mars 1 vehicle response to a $1.0^{\circ}$ step attitude command.

Some simulations were performed to determine the impact of lateral or side-to-side propellant slosh on TVC requirements. Propellant slosh was modeled using a pendulum mass to represent the effective propellant mass that moves during sloshing (Ref. 5). This method is good for this simulation because the slosh frequency varies automatically with vehicle acceleration. For the Mars vehicle four additional masses were added; one for each propellant tank.

One approach to tuning the controllers in this simulation is to examine the response to a step input attitude command. While not representative of a likely maneuver during a mission, it gives insight into the performance of the overall system. Figures 7 and 8 show responses to $0.5^{\circ}$ and $1.0^{\circ}$ step commands in pitch attitude for the Mars 1 case. Vehicle attitude shows modest overshoot and overall acceptable behavior. Peak engine gimbal angles are about $3^{\circ}$ and $5^{\circ}$. The vehicle system takes about $10 \mathrm{sec}$ to get within 99 percent of steady state driven by the available engine thrust, gimbal rate and vehicle inertia. All other cases showed similar behavior for the same controller and TVC settings, except for the $1^{\circ}$ step for the Apophis 2 case, which is the lightest vehicle case. The vehicle attitude control went unstable for this case. The initial response of the system got the vehicle rotating at a rate such that the TVC system could not recover. The $0.5^{\circ}$ step simulation for Apophis 2 was acceptable. Based on all of the step response results, the controller and TVC parameters were assumed to be acceptable for preliminary TVC investigations. Note on a real vehicle it would not be unusual to change the values of controller gains as the vehicle properties change throughout the mission, gain scheduling, but for these studies they were kept constant.

\subsection{Simulation Results}

\subsection{Engine Start}

Various scenarios were simulated to determine performance requirements of a TVC system. The first scenario is for an engine start case with engine thrust profiles as shown in Figure 9. For this scenario, engine 1 thrust buildup is assumed to lag thrust output of the other two engines by $10 \mathrm{sec}$. This puts a moment on the vehicle about the $\mathrm{z}$ axis (yaw axis). All engines have the same thrust when they reach 100 percent, so thrust asymmetry ends. The engines are located equidistant about the vehicle $\mathrm{x}$ centerline.

Figure 10 shows results for the two Mars vehicle cases. Results are very similar for both cases with a maximum engine yaw gimbal angle of $1.85^{\circ}$. The commanded gimbal angles were the same for all three engines and all simulated engine gimbal angles were uniform among the engines. For comparison, a $5 \mathrm{sec}$ lag in engine 1 thrust buildup resulted in a $1.11^{\circ}$ maximum engine gimbal angle. 


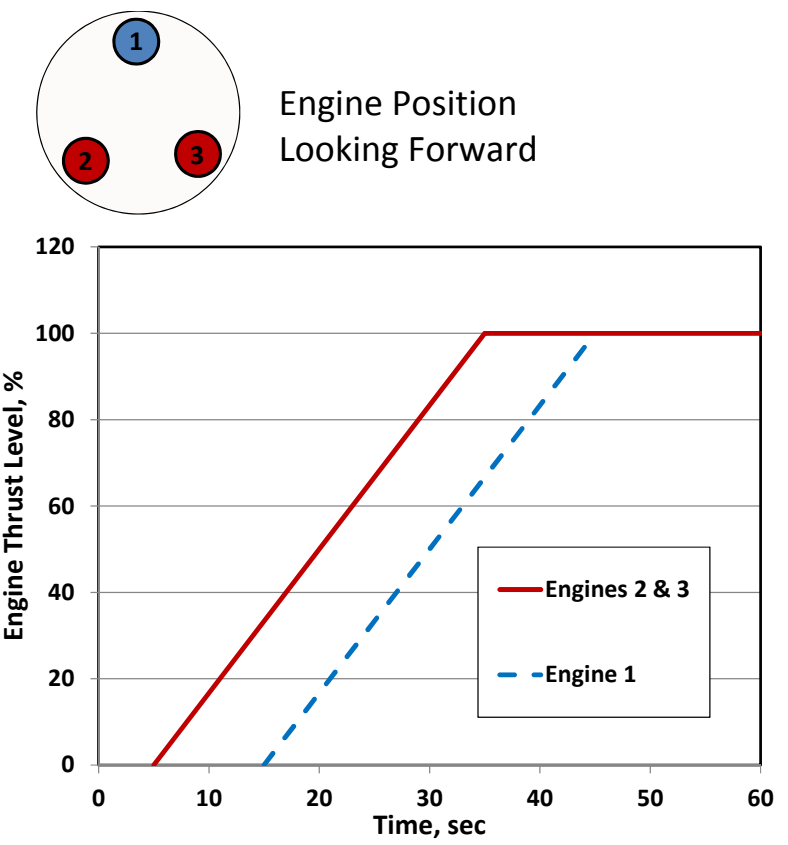

Figure 9.-Engine start transient.

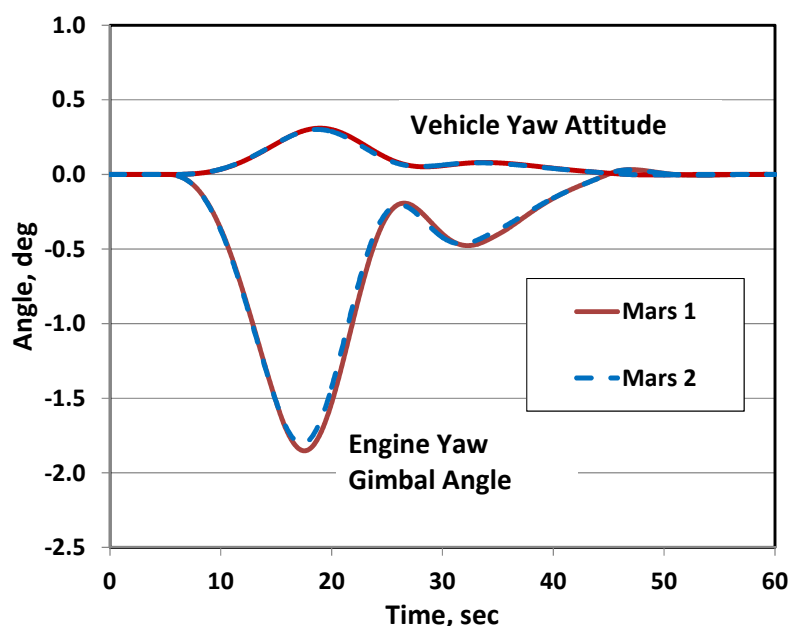

Figure 10.-Engine start transient with engine 1 thrust lag, Mars vehicle.

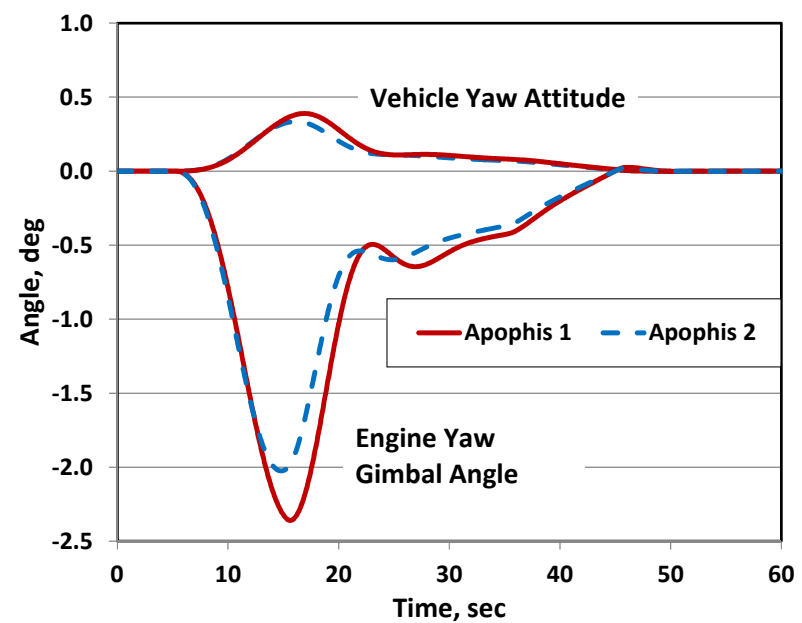

Figure 11.-Engine start transient with engine 1 thrust lag, Apophis vehicle.

The Apophis vehicle cases are shown in Figure 11. The case for initial burn, Apophis 1, has a maximum engine yaw gimbal angle of $2.36^{\circ}$. The lighter vehicle case, Apophis 2, reaches a maximum gimbal angle of $2.02^{\circ}$. Note the actual Apophis 2 case is defined at the end of a last engine burn so an engine start is not an expected operation. However, all of these cases and results are useful for showing general effect of vehicle properties on TVC requirements, which is the intent for this study.

The relative gimbal angles for the various cases are a function of vehicle mass moment of inertia and also vehicle center of gravity location. The lighter Apophis vehicle reacts more to the engine start thrust asymmetry, resulting in higher vehicle yaw attitude and higher engine gimbal angles, compared to the Mars vehicle. For each vehicle, as the mission progresses the vehicle center of gravity moves as propellant is used. This movement may lessen or it may improve the effectivess of the vectored engine thrust depending on the direction of the movement. The greater the distance from the engines to CG, the greater the moment arm from which the engines create a moment about the vehicle CG. 


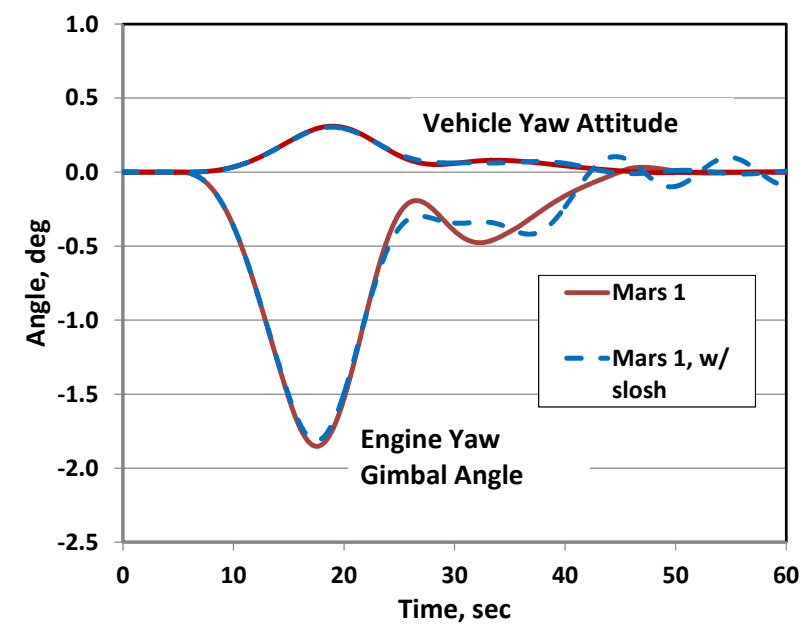

Figure 12.-Engine start transient with engine 1 thrust lag, with propellant slosh, Mars 1 case.

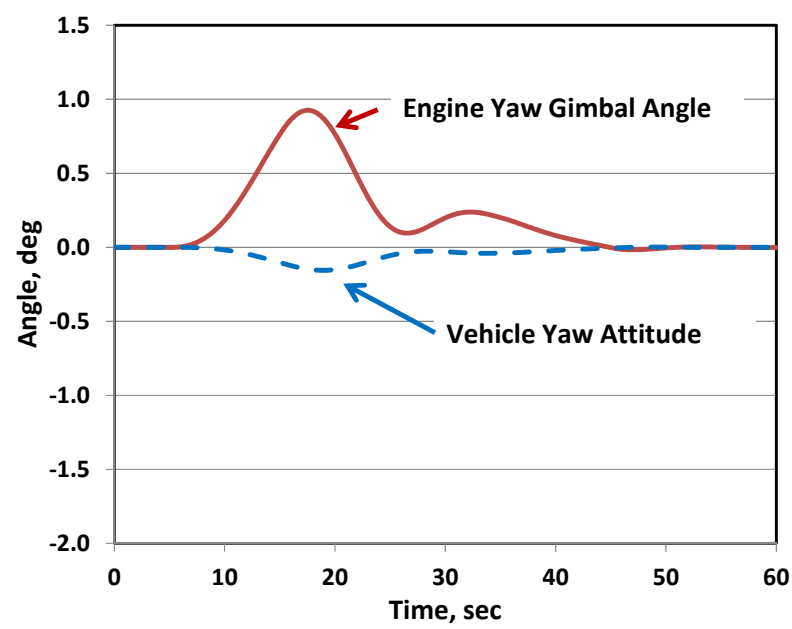

Figure 13.-Engine start transient with engine 2 thrust lag, Mars vehicle case 1 , yaw axis.

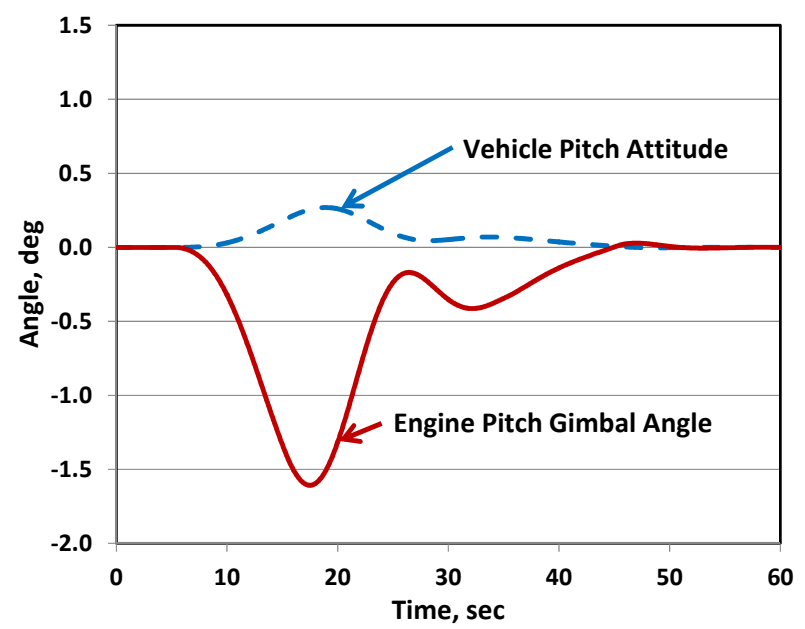

Figure 14.-Engine start transient with engine 2 thrust lag, Mars vehicle case 1 , pitch axis.

The effect of propellant slosh is shown in Figure 12 for the Mars 1 case. The initial gimbal transient with slosh is almost identical to the non-slosh scenario, with peak gimbal amplitude slightly smaller. There are very slight oscillations in yaw attitude and engine gimbal angle at the slosh frequency of about $0.091 \mathrm{~Hz}$ (the slosh frequencies are almost the same for all four tanks because they all have the same diameter and all have about the same fill levels). Although no slosh damping is assumed in the model, the oscillations do eventually die down due to some damping in the attitude controller. This scenario illustrates that the slosh effects are more a factor for controller design and do not significantly impact TVC actuator requirements.

Figures 13 and 14 show a start transient scenario where engine 2 has a $10 \mathrm{sec}$ thrust lag. In this case there are thrust moments about the pitch and yaw vehicle axes, resulting in engine gimballing about both axes. The individual gimbal movements are less than in the previous case, though the maximum total gimbal angle, (pitch angle ${ }^{2}+$ yaw angle $\left.{ }^{2}\right)^{1 / 2}$ equals $1.85^{\circ}$, is the same magnitude as before, as expected.

Note if one engine starts early (or two engines start late) the initial moment on the vehicle will not be as severe, so this scenario, with a lag for one engine, represents the worst case of start lead or lag for a three engine cluster. Startup will be examined in more detail in a later section. 


\subsection{Engine Shutdown/Cool Down}

The total shutdown operation from 100 percent thrust may involve multiple temperature and pressure profiles and hold periods that are different depending on reactor operating time. The nominal 3 engine shutdown for this study was assumed to end with a linear thrust ramp down over a period of $3 \mathrm{~min}$, starting at the 10 percent thrust level. As in the start-up case, it is likely that there may be variations among the engines that result in a net thrust asymmetry. This asymmetry will become more critical as the thrust levels decrease and TVC becomes less effective. Figure 15 shows the shutdown scenario with engine 1 lagging the other two engines by $20 \mathrm{sec}$ over the final $2 \mathrm{~min}$ of the early cool down period. At the end of the $3 \mathrm{~min}$ ramp down all the engines continue producing 0.2 percent of nominal thrust. This very low thrust level represents the thrust produced from the initial cooling flow during the pulse phase and may continue for many minutes or until the engine is started up for another burn (as in the case of the 1 st and 2 nd perigee burns). Some of the values in this scenario are based on an analysis of NERVA engine operations (Ref. 6).

The Mars 2 case was used for this analysis because it represents the Mars vehicle at the end of the 1st perigee burn. Propellant slosh was turned on for this run. Figure 16 shows the results for the shutdown scenario with engine 1 lagging by $20 \mathrm{sec}$. As the shutdown continues, a small yaw attitude error begins growing due to the thrust imbalance. At about $180 \mathrm{sec}$ into the scenario, when engine engines 2 and 3 reach the 0.2 percent thrust level the attitude begins changing more quickly. Gimbal angle reaches a peak of $2^{\circ}$ while yaw attitude remains within $0.36^{\circ}$. It appears that TVC is barely able to maintain control of the vehicle for this scenario. The timing at the end of shutdown is critical; a slightly larger thrust asymmetry during shutdown might have prevented TVC from controlling the vehicle. In all likelihood RCS would be required to ensure timely attitude control during shutdown.

Engine thrust for an off-nominal engine failure case is shown in Figure 17. Engine 1 is assumed to drop to zero thrust over $10 \mathrm{sec}$ which puts a yaw torque on the vehicle as engines 2 and 3 continue operating. Figure 18 shows the response of the Mars vehicle when the engine thrust changes. Peak gimbal angle reaches $1.70^{\circ}$ for the heavier vehicle and slightly less for the Mars 2 case. Vehicle attitude is well behaved, though a constant attitude error persists due to the constant thrust disturbance. Figure 19 shows the result for the same engine failure scenario for the Apophis vehicle. Peak engine gimbal angles reach $1.92^{\circ}$ for the Apophis 1 case and $1.70^{\circ}$ for the lighter vehicle case. Again the vehicle attitude response is well behaved.

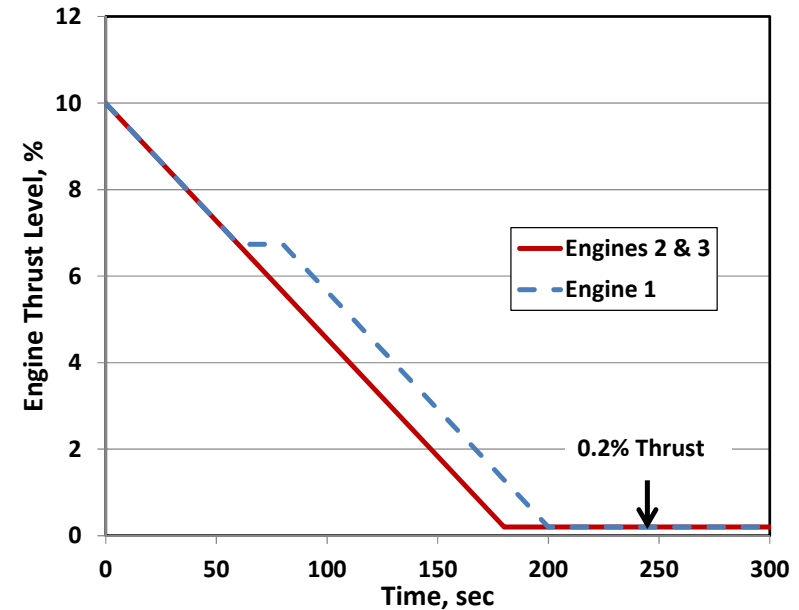

Figure 15.-Engine thrust for 3 engine shutdown/ cool down transient with 20 sec lag for engine 1.

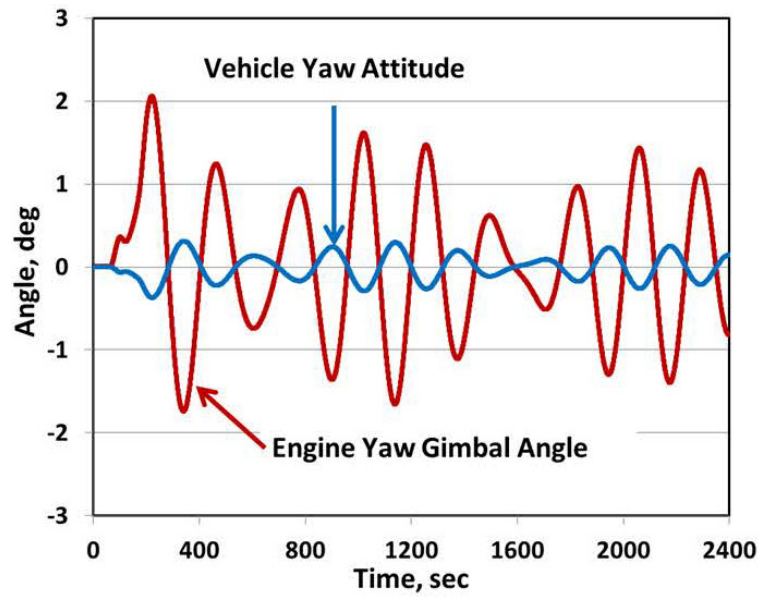

Figure 16.-Vehicle response to 3 engine shutdown/ cool down transient with $20 \mathrm{sec}$ lag for engine 1. Mars 2 case, with propellant slosh. 


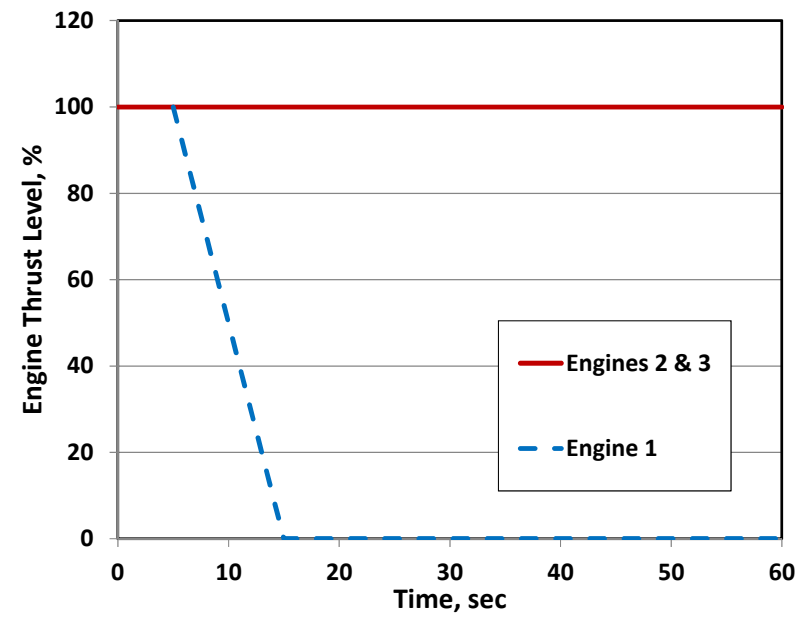

Figure 17.-Engine thrust for off-nominal engine 1 failure scenario.

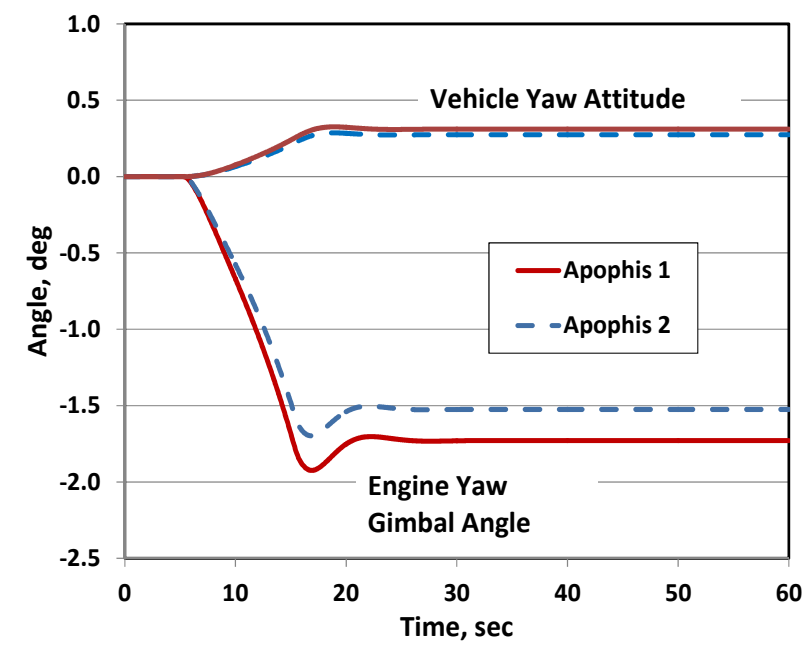

Figure 19.-Off-nominal engine 1 failure, Apophis vehicle response.

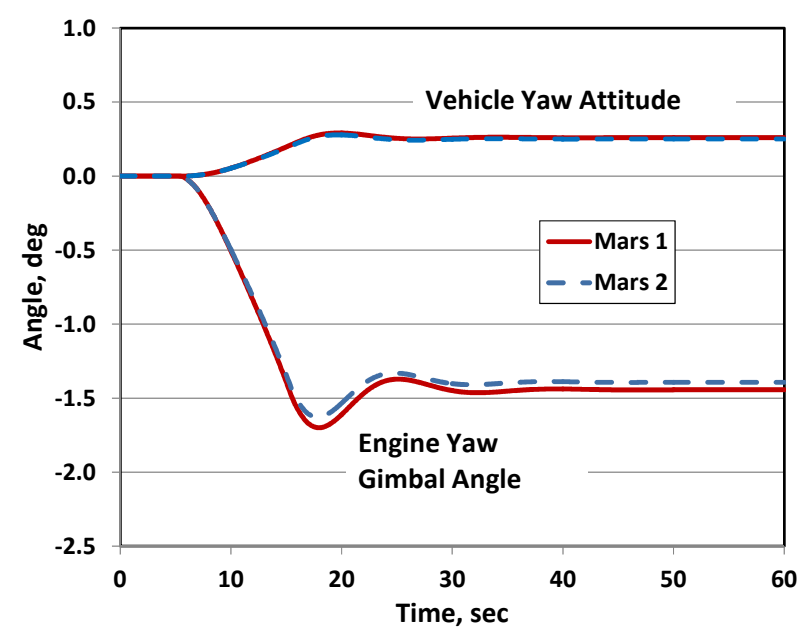

Figure 18.- Off-nominal engine 1 failure, Mars vehicle response.

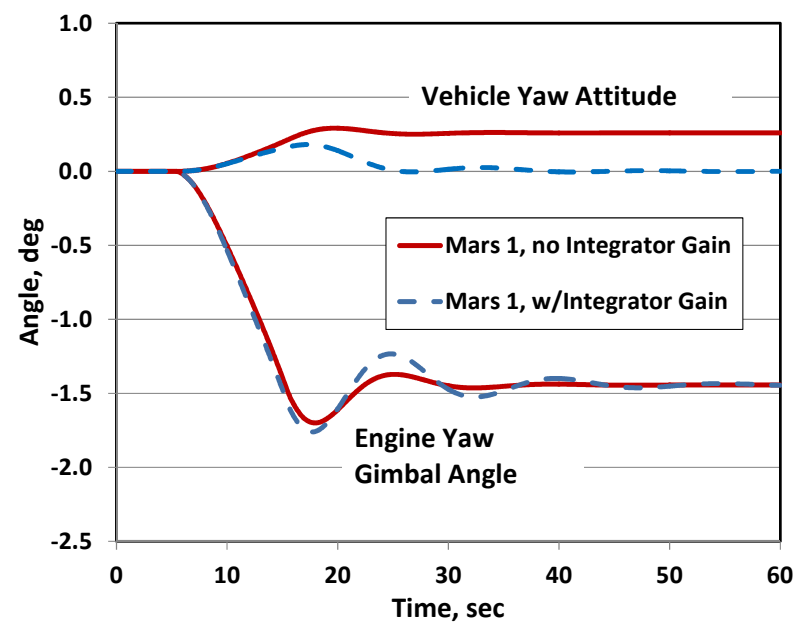

Figure 20.-_Off-nominal engine failure, effects of integrator gain in attitude controller, Mars 1 case.

The steady state attitude error in these engine failure scenarios can be reduced by increasing the proportional gain in the attitude controller or can be practically eliminated by adding an integrator to the controller. Both of these actions tend to make the system less stable, so changes are not automatically warranted. Figure 20 shows the effects of adding the integrator in the attitude controller for the Mars 1 case. Maximum gimbal angle and gimbal rate are increased just slightly, oscillations are more pronounced, and attitude error goes to zero. Unless noted, results are for simulations without the integrator in the attitude controllers.

The steady state gimbal angle is the angle that puts the net thrust through the vehicle CG. In the Mars 1 case with engine 1 out, the net thrust location is $-1.035 \mathrm{~m}$ from the vehicle centerline on the $y$ axis (the y coordinates of both engines 2 and 3, note the $\mathrm{z}$ coordinates cancel out so there is no pitch moment). The vehicle body CG is $42.35 \mathrm{~m}$ from the engine gimbal points. Taking the arctangent of (1.035/42.35) yields $1.40^{\circ}$, close to simulated value of $1.44^{\circ}$. More precise calculations would include the small effect due to the fact that the engine net thrust does not pass through the net engine $C G$ when one engine is out. This effect is automatically included in the model. 
It is worth noting that getting to zero attitude in this simulation, which makes the vehicle body axis aligned with the inertial $x$ axis, is not the same as flying in the inertial $x$ direction. The vehicle flies in the direction of the thrust from the engines, not in the direction of vehicle body alignment. To fly in the pure $\mathrm{x}$ direction, the attitude command needs to match the actual gimbal angle, putting the thrust in the pure $x$ direction. A real attitude controller would use inertial guidance information to derive the vehicle attitude necessary to get the thrust in alignment with the desired trajectory. The inertial guidance function is not included this simulation because it not important for the derivation of TVC requirements.

\subsection{Thrust Vector-CG Offset}

As in the engine out case, a CG offset in the vehicle body also results in steady state gimbal angles to maintain steady vehicle attitudes. For a $2.0 \mathrm{~m}$ offset in the y axis in the vehicle body CG, a steady state yaw engine gimbal angle of $2.70^{\circ}$ results, shown in Figure 21. This is exactly the value obtained from the calculation that puts the net engine thrust through the vehicle body CG; arctangent (2.0/42.35) yields $2.70^{\circ}$. In general, CG offsets would likely be much smaller the $2.0 \mathrm{~m}$ throughout the mission. For the Mars vehicle, however it should be noted that if the two side-by-side drop tanks are not emptied simultaneously there will be a CG offset.

A TVC failure is simulated in Figure 22. For this scenario it is assumed that one of the engine gimbal actuators, pitch on engine 2 , fails to a $2.0^{\circ}$ engine angle. The pitch actuator on the other two engines, engines 1 and 3 , eventually settle to a $1.0^{\circ}$ pitch gimbal actuator to counterbalance the thrust on the engine with the failed actuator. In general for any single bias failure of a gimbal actuator, the response of the other two actuators will be one half the value of the failed position (for a three engine cluster).

As noted before, various combinations of thrust vector offsets and CG offsets can be combined to determine the net effect on gimbal angle requirements.

\subsection{Steering Maneuvers}

Figure 23 shows results from a commanded pitch attitude maneuver for the Mars 1 case. The maneuver includes attitude commanded rates of $\pm 0.1^{\circ}$ per second. Peak engine gimbal angles are about $1.5^{\circ}$. Vehicle pitch attitude stays close to commanded attitude. Figure 24 shows the Apophis 1 case with the same commands. Peak gimbal angles are about $1.25^{\circ}$.

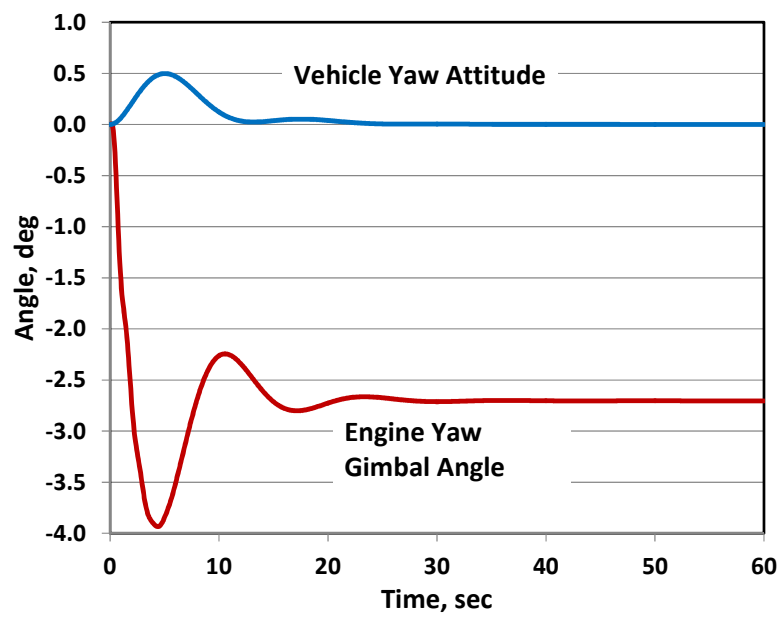

Figure 21.-CG offset of $2.0 \mathrm{~m}$ at time $=0$. Mars 1 case, with integrator gain.

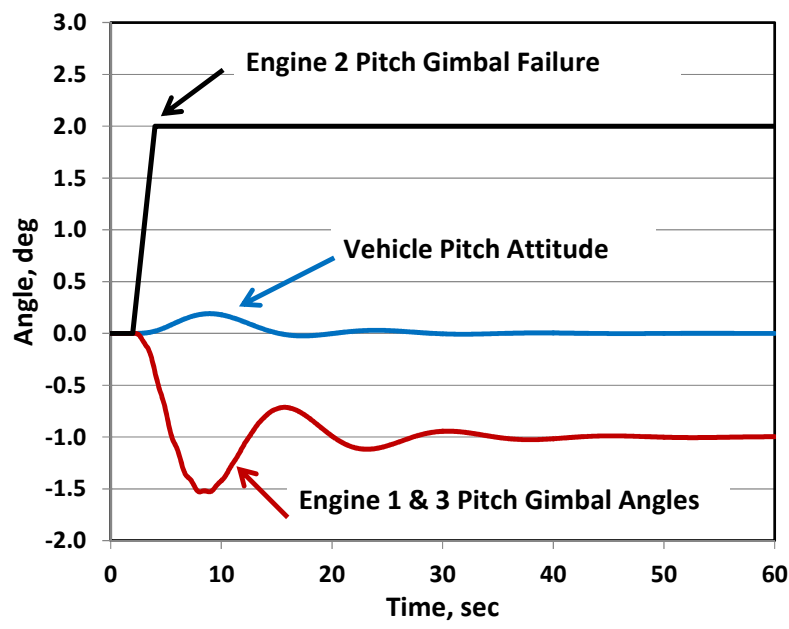

Figure 22.-Off-nominal TVC failure of engine 2 pitch gimbal to $2^{\circ}$, Mars 1 case, with integrator gain. 


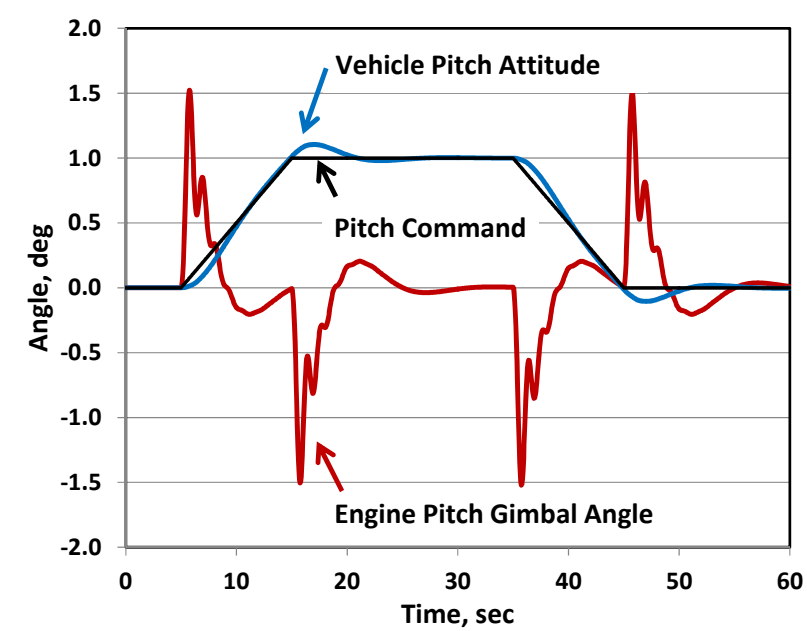

Figure 23.-Pitch attitude maneuver, $0.1^{\circ}$ per second, Mars 1 case.

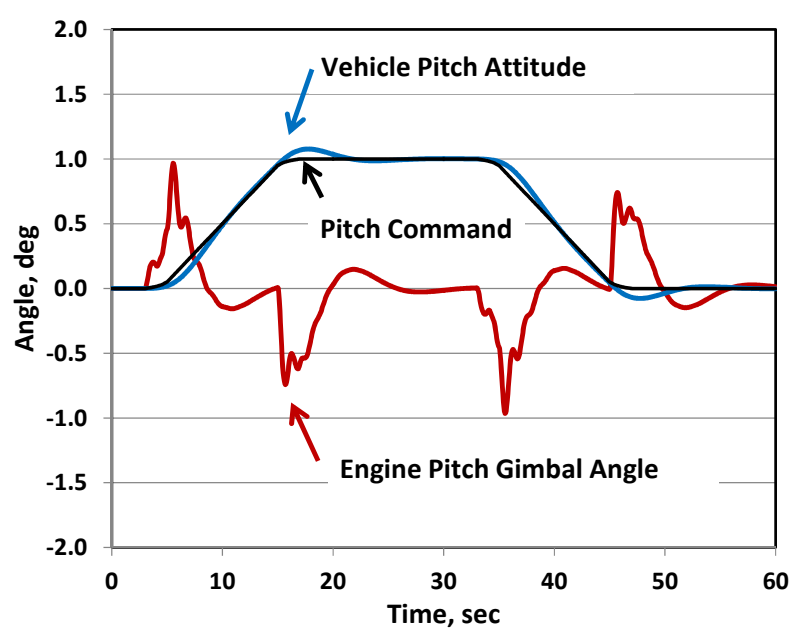

Figure 25.-Pitch attitude maneuver with command smoothing, Mars 1 case.

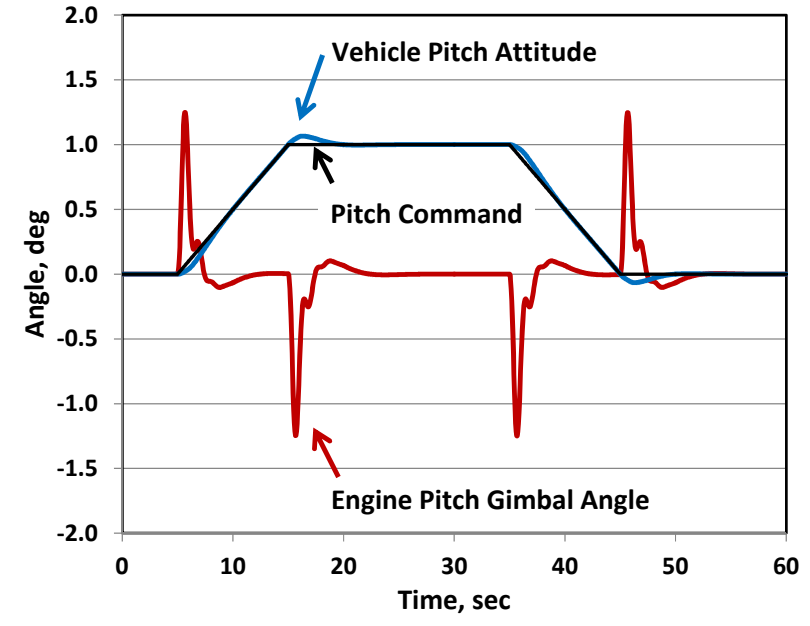

Figure 24.-Pitch attitude maneuver, $0.1^{\circ}$ per second, Apophis 1 case.

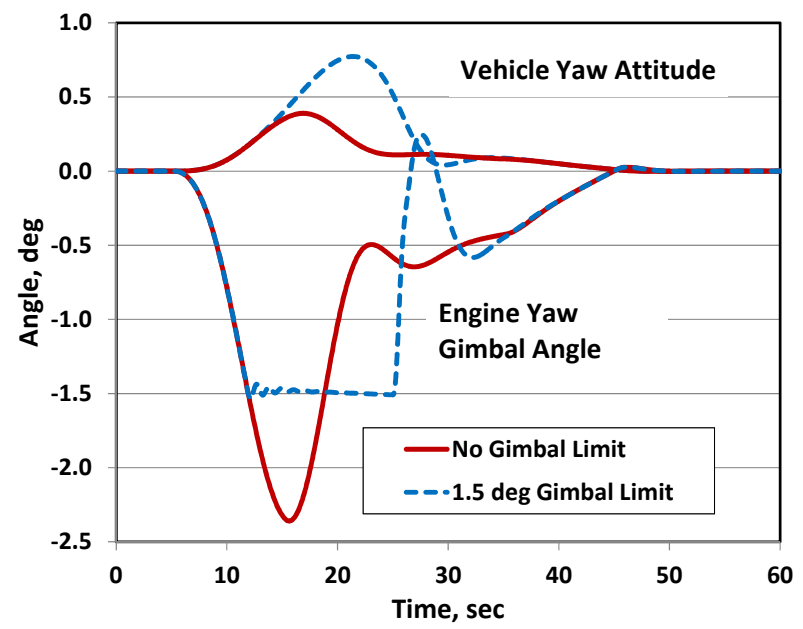

Figure 26.-Engine start transient, engine 1 with $10 \mathrm{sec}$ lag, Apophis 1 case.

The commanded maneuver in the previous examples is not one that would be expected for a real mission. Transitions between various attitude rates would undoubtedly be smoothed to avoid exciting vehicle structural modes (Ref. 7). An example of the impact of smoothing the rate transitions is shown in Figure 25, for the Mars 1 case. Peak gimbal angles are between $0.7^{\circ}$ and $1.0^{\circ}$.

\subsection{Gimbal Range Summary}

Most of the steady state type scenarios, such as CG offset, impact gimbal range but not rate. Unless it is a sudden and drastic change, (such as engine out) timing is not important. The gimbal angle for trim conditions can be determined from straight forward geometry calculations (in general involving calculations of non-planar engine thrusts and offsets). The difficult part is determining the values that need to be considered and how they should be combined.

For transient cases, limiting the engine gimbal range will affect the performance of the TVC system. Figure 26 shows the impact of limiting the gimbal range to $1.5^{\circ}$ for an Apophis 1 case startup scenario. Vehicle attitude excursion almost doubles from $0.39^{\circ}$ to $0.77^{\circ}$. The magnitude of the attitude excursion for this scenario may or may not be significant. The key is to ensure that the vehicle remains controllable 
and this will depend on a number of factors including TVC and RCS capabilities. Application of bias angles for $\mathrm{CG}$ offsets and other corrections for various deviations reduces the effective gimbal range and may make it non-symmetric.

\subsection{Gimbal Power Requirements}

Gimbal power requirements are dependent on the gimbal actuation torque and gimbal rotation rate. As noted, some of the scenarios were presented for illustrative purposes and do not represent expected operations. These scenarios, such as the steering maneuver, should not necessarily be used to drive TVC requirements. Responses for other scenarios, such as start transient and off-nominal shutdown are dependent on variables that are difficult to quantify at this time (engine thrust variability during start up, engine thrust shutdown rate for off-nominal shutdown). If we can at least bound these scenarios we have a basis for establishing requirements relating to power.

Startup transient for the Apophis 1 case was examined more closely because it showed the most reaction to the start transient (largest gimbal angle and rate) among the vehicle cases examined. Various combinations of engine 1 thrust lag were examined. Results are shown in Figure 27 for start lags of 5 to $20 \mathrm{sec}$. The results for the beginning of each run are the same, during the time that engines 2 and 3 are ramping up in thrust while engine 1 remains off. Once engine 1 starts ramping up the vehicle attitude and engine gimbal angle results start to diverge. Figure 28 shows gimbal rate versus gimbal angle for the four simulation runs. Peak gimbal angle was $2.37^{\circ}$ and peak rate was $0.38^{\circ}$ per second.

A different startup scenario was examined to determine effects on TVC. For this scenario, engine 1 was assumed to start at the same time as the other two engines but it has a slower rate of thrust build up. This situation is designated as a prolonged start, e.g., engine 1 took 5 or $10 \mathrm{sec}$ longer than the nominal $30 \mathrm{sec}$ to reach 100 percent thrust. These runs, shown in Figure 29, are more benign in terms of vehicle attitude and gimbal angles and rates.

If off-nominal shutdown is included as a design case for these NTR missions, it should be examined in more detail. The key unknown variable is the thrust decay profile for an engine that fails during a thrusting period. The most extreme scenario would be a sudden and complete halt of thrust for an engine. More plausible scenarios may include a time period over which the thrust decays. Simulation runs for shutdown duration for engine 1 ranging from 0 to $20 \mathrm{sec}$ are shown in Figure 30. Gimbal rate versus gimbal angle is shown in Figure 31. The step transient $(0 \mathrm{sec})$ thrust run, indicates a gimbal rate of $1.85^{\circ}$ per second, which is much higher than needed for the other runs with less abrupt engine shutdowns. Maximum gimbal angle was $2.29^{\circ}$.

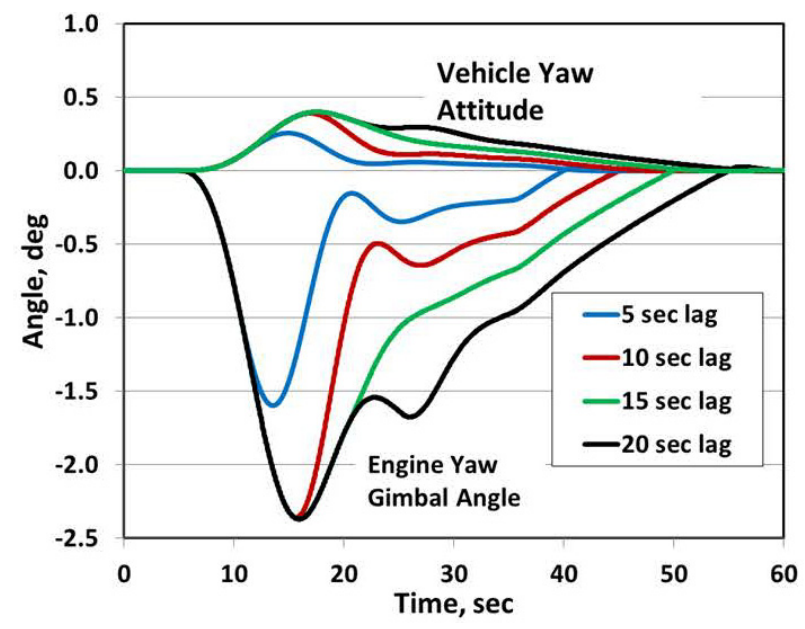

Figure 27.-Engine start transients with various lags in engine 1 thrust, Apophis 1 case.

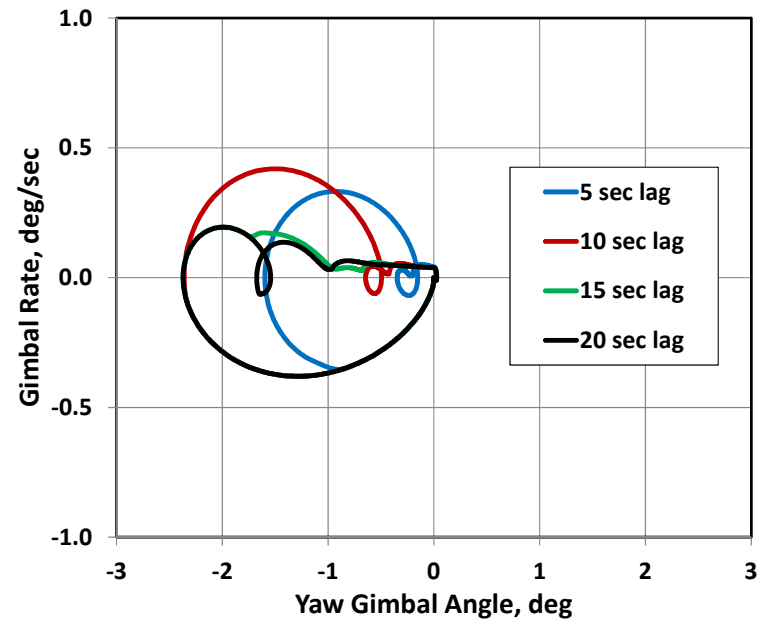

Figure 28.-Engine start transients with various lags in engine 1 thrust, Apophis 1 case. 


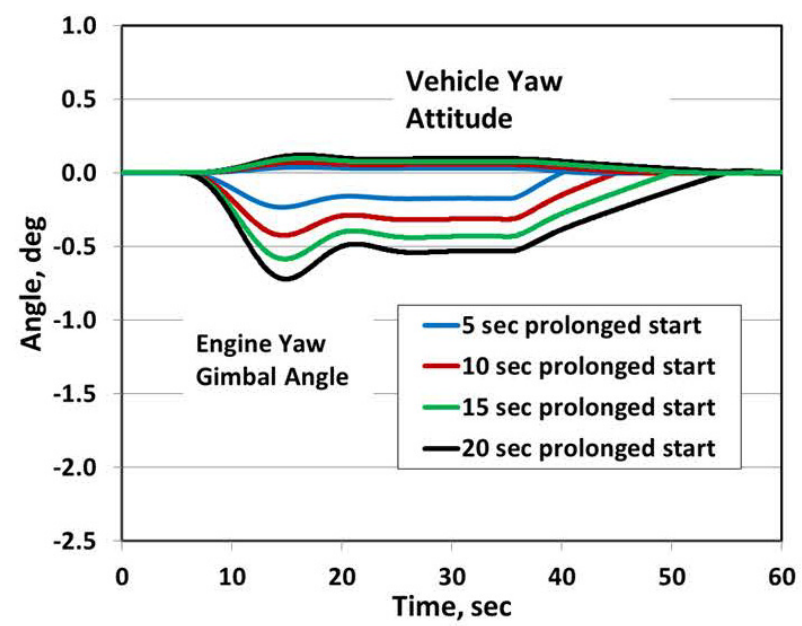

Figure 29.-Engine start transients with various prolonged engine 1 thrust profiles, Apophis 1 case.

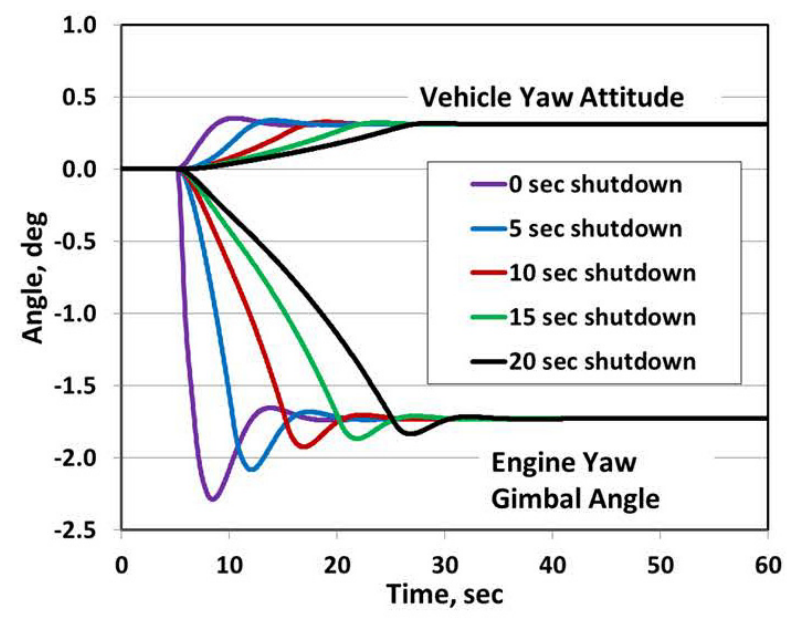

Figure 30.-Engine shutdown transients with various shutdown durations for engine 1 thrust, Apophis 1 case.

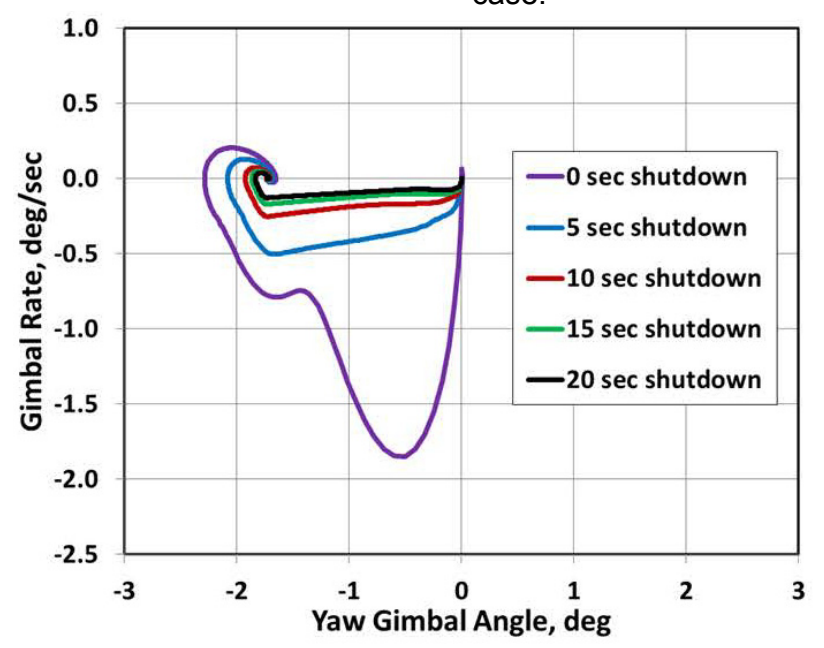

Figure 31.-Engine shutdown transients with various shutdown durations for engine 1 thrust, Apophis 1 case.

The gimbal rate capability in these analyses is dependent on the actuator torque. The commanded torque is dependent on attitude and actuator controller gain settings, subject to an imposed actuator torque limit. For the step transient run, the peak actuator torque was $2915 \mathrm{Nm}$ which was below the torque limit setting of $4000 \mathrm{Nm}$, so the torque limit was not a factor restricting gimbal rate.

The gimbal torque is the other factor, along with gimbal rate, that determines gimbal actuator mechanical power. There are a number of sources of gimbal torque. Within the model, these torques are summed to produce a net torque that accelerates the engine about the gimbal axes.

These torques include:

- Actuator Torque - As previously described this is the driving torque, provided by an actuating mechanism. The actuator is commanded by the controllers to produce the desired vehicle attitude.

- Gimbal Bearing Friction Torque - This represents the friction of the gimbal bearing. For these analyses, gimbal friction is assumed to act as viscous friction; the friction torque is proportional to gimbal rate. The gimbal friction should be the same for all of the engines and the same for each gimbal axis, within tolerance values. 
- Propellant Duct Spring Torque-As the engine gimbals, the $\mathrm{LH}_{2}$ propellant duct(s) between the tanks and the engines must flex, usually by means of a bellows section. As the duct bends it exert a moment on the engine because the duct acts as a spring element. The torque value is proportional to the engine deflection angle. Duct spring torques should be same for all engines. Depending on the configuration of the propellant ducts, the spring torque may be different in pitch and yaw axes. Ducts may also contribute to friction (not modeled in these simulations).

- Engine Thrust Offset - If the effective thrust of the engine does not pass through the center of the gimbal, there will be a torque about the gimbal. The torque is equal to thrust times the thrust offset. Often, this torque is among the largest sources of gimbal actuator load. The thrust offset is unique for each engine; it is ideally near zero, and can be in any orientation.

- Longitudinal Acceleration of Engine CG-As the engine gimbals, the center of mass of the engine moves off axis relative to the longitudinal acceleration of the gimbal. This results in a torque about the gimbal. This torque is automatically calculated in the model.

- Lateral Acceleration of Engine Gimbal-Any lateral acceleration of the vehicle at the engine gimbal will result in a torque due to a reaction with the engine mass moment of inertia. This torque is also accounted for in the simulation model.

- Propellant Momentum - As the propellant flows through the ducts on the engine, a change of direction will impart a reaction load on the engine. These effects are relatively small and are not included in current analyses.

- Engine Turbopump Loads - The engine turbopump (or pumps) will impart reaction loads on the engine as it changes speed and will resist engine gimballing due to gyroscopic effects. These effects are expected to be small and are not in included in the current model.

- Engine Rotational Inertia Load -As mentioned, engine acceleration is a resulting output of all torques summed about the gimbal. Peak engine acceleration for simulation runs was about $5 \% \mathrm{sec}^{2}$. This indicates a net peak torque applied to the engine of about $2000 \mathrm{Nm}$, for an engine inertia of $23,000 \mathrm{~kg}-\mathrm{m}^{2}$ about the gimbal axis.

Various values of engine thrust offset, gimbal bearing friction, and duct spring torques were examined to determine effects on gimbal actuator torque and power requirements. Figure 32 shows the results of parametric variations for the engine 1 step transient shutdown for the Apophis 1 vehicle, which

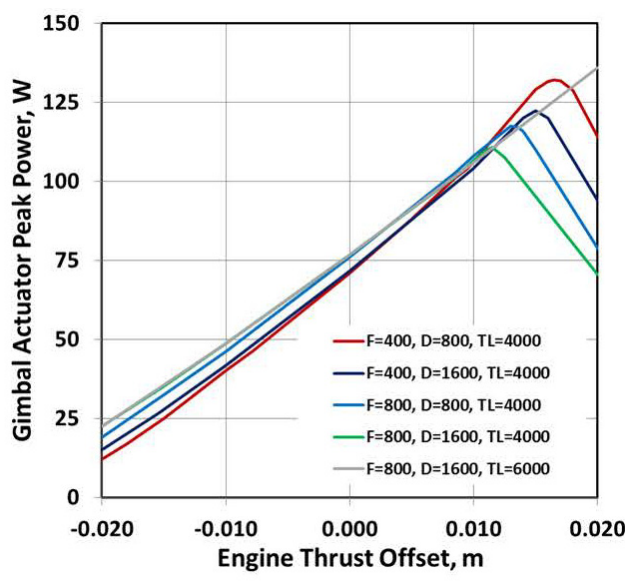

Figure 32.-Gimbal actuator peak power versus engine thrust offset for the step transient off-nominal engine 1 shutdown, Apophis 1 case. Parametric factors: Gimbal Friction - F Nm/(deg/sec), Duct Spring Torque - D, Nm/deg, Actuator Torque Limit - TL, Nm. 
was the most severe case for engine gimbal rate. The curves show peak actuator power that resulted from a series of simulation runs with different settings for engine thrust offset, gimbal bearing friction factor and duct spring constant. Peak power is the maximum transient mechanical power output demand from one yaw gimbal actuator.

Thrust offset is by far the largest contributor to gimbal actuator torque and power requirements. Peak actuator power increases as thrust offset moves from negative to positive values. For this scenario, negative thrust offset is aiding the movement of engine 2 that is commanded to respond to the sudden shutdown of engine 1. Positive thrust offset opposes engine motion. At high positive values of thrust offset the peak power decreases for the simulation, as a result of the actuator torque limit being reached. One set of runs was made with a wider actuator torque limit, $\pm 6000 \mathrm{Nm}$, resulting in a continuous curve, without a rollover.

During these scenarios there are times when the actuator must act as a brake to reduce engine rotational velocity, indicated as negative power. The polarity of power depends on polarity of both gimbal torque and gimbal rate. Duct spring torques can aid the actuator when gimbal direction is returning towards zero gimbal angle.

For each of the maximum peak power simulations runs in Figure 32, a time history of actuator power is shown in Figure 33. All the runs were for values of positive thrust offset (except a baseline case with nominal values and zero thrust offset). It can be seen that the general power response to the engine thrust step is a sharp power peak followed by a power reversal as the engine rotation is accelerated then decelerated. The duration of the power transient is about $15 \mathrm{sec}$. It is evident that the higher frequency variation in the power trace is influenced by the values of gimbal friction and duct spring constant.

Gimbal angle and vehicle attitude are shown for these same simulation runs in Figure 34. Most of the outputs are similar. The two cases with the $1600 \mathrm{Nm}$ per degree propellant duct spring constants, with the lower actuator torque limit have gimbal angles that are limited and as a result the vehicle attitude excursions are relatively high.

Based on these results and assumptions of likely thrust offset and other values, it appears that mechanical actuation power of $140 \mathrm{~W}$ should be adequate for these types of missions. The largest factor for actuator power is engine thrust vector offset. Peak gimbal torque capability of $4000 \mathrm{Nm}$ would be adequate.

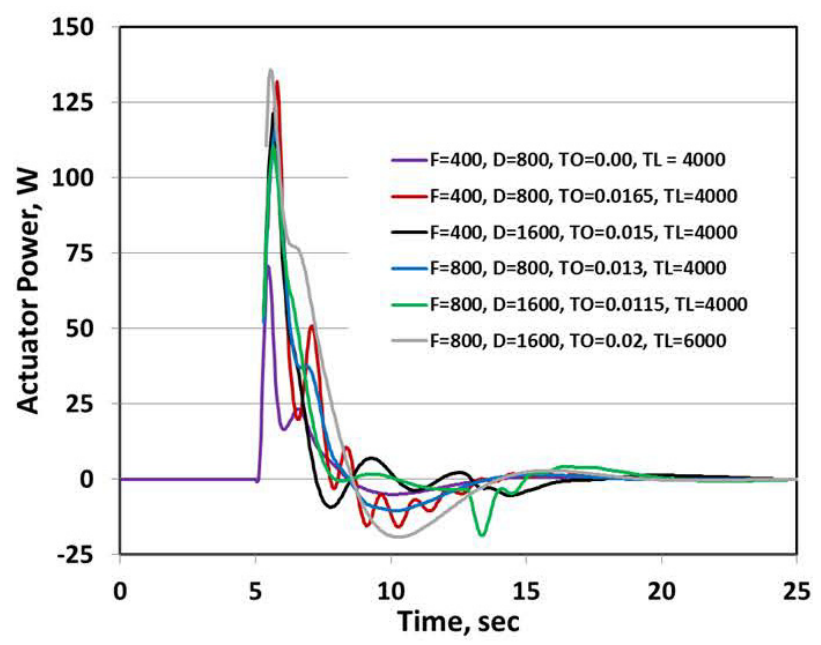

Figure 33.-Gimbal actuator power for step transient offnominal engine 1 shutdown, Apophis 1 case.

Parametric factors: Gimbal Friction - F, Nm/(deg/sec), Duct Spring Torque - D, Nm/deg, Torque Offset - TO, $\mathrm{m}$, Actuator Torque Limit - TL, Nm.

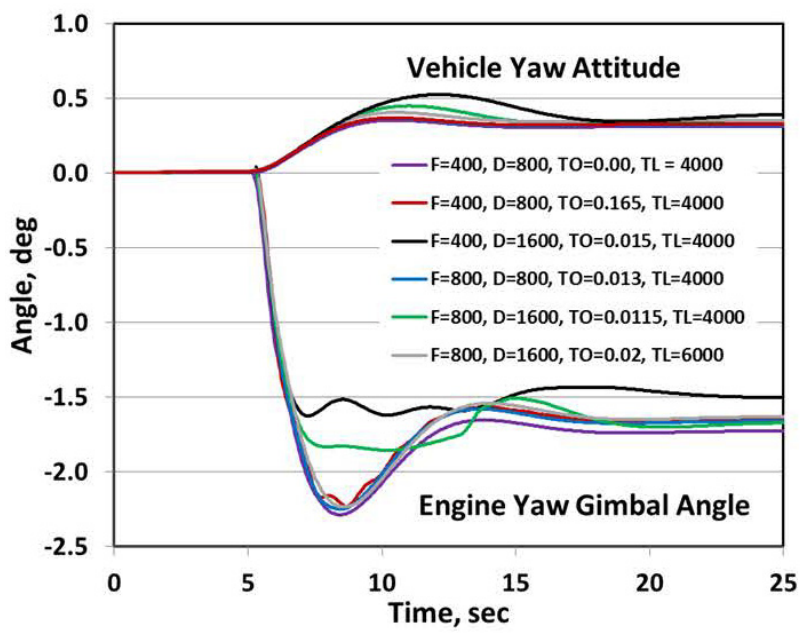

Figure 34.-Engine shutdown transients with various torque variables for step transient off-nominal engine 1 shutdown, Apophis 1 case. Parametric factors: Gimbal Friction - F, Nm/(deg/sec), Duct Spring Torque - D, $\mathrm{Nm} / \mathrm{deg}$, Torque Offset - TO, m, Actuator Torque Limit - TL, Nm. 


\subsection{TVC Actuation Options}

There are several options for engine gimbal actuation for thrust vector control. For this application, unique mission environments and long mission durations affect the selection of technologies. In particular, high gamma and neutron radiation is present in the vicinity of the reactors of the NTR engines. Certain materials including organics and electrical components are particularly affected by radiation. Technologies that are more inherently immune to radiation effects are preferred. Due to long mission times and flight paths faraway from Earth, components exposed to deep space will see cold environments and may require thermal control.

The power requirements of the actuators also influence the technology selections. Some options are practical only for low power applications, while other technologies such as hydraulic actuation have been used successfully for the highest power applications. Conventional rockets have used hydraulically powered actuators for many years. Typically, a pair of linear hydraulic actuators connects between the structure of the vehicle and the rocket engine.

Electric actuation for TVC can be implemented in many ways. The electromechanical approach uses an electric motor coupled to a gearbox that actuates a screw mechanism to provide linear motion. Numerous configurations of motors, gearing and screw mechanisms are possible, depending on redundancy requirements. Other approaches for electric actuation use hydraulic components for converting electric rotary motion to linear motion.

With an electromechanical actuator, it is likely that there would be a need for a motor brake to hold load, between transient events, particularly if the actuator uses a low friction ball screw or roller screw.

Electric actuation also has a long heritage for space applications at relatively low power levels including the Apollo service module main engine gimbal actuator, the Shuttle Orbital Maneuvering System engine gimbals and for RL-10 engines on upper stage applications. The new Vega rocket uses electromechanical actuators for all 4 stages with actuator powers of $17.5 \mathrm{~kW}$ to $90 \mathrm{~W}$ mechanical output (Ref. 8).

Based on the relatively modest power requirements indicated in these results, electromechanical actuation for TVC appears to be well suited for these NTR vehicles. There should also be commonality with other actuation needs on the NTR engine, including valve actuation and reactor control drum actuation. For both of these applications, electric actuation was the selected technology for the NERVA program. Radiation tolerant electric motors are used in the nuclear power industry.

Controllers for electric actuators should be located as far away from radiation sources as possible. For vehicles that carry human crew, there would be additional shielding at the base of the vehicle.

Table 3 shows some preliminary estimates for peak electrical power sizing, including typical losses and conversion efficiencies. For initial sizing estimates mechanical power for actuation is rounded up to $200 \mathrm{~W}$. It should be emphasized that during most of the flight, the TVC system would not be moving the engines and the electrical power requirements would be reduced to a low level for controller housekeeping power and the power to maintain the electric motor brake.

TABLE 3.-ELECTRIC POWER REQUIREMENTS

\begin{tabular}{|l|c|}
\hline & Peak \\
\hline Peak mechanical output power, W & 200 \\
\hline Mechanical transmission efficiency & 0.64 \\
\hline Motor efficiency & 0.64 \\
\hline Electrical cable efficiency & 0.97 \\
\hline Motor driver efficiency & 0.85 \\
\hline Single actuator, subtotal, W & 592 \\
\hline Electric brake power, W & 30 \\
\hline Single actuator electrical total power, W & 622 \\
\hline Single engine (two actuators) total power, W & 1244 \\
\hline
\end{tabular}


For the power levels required, an electromechanical actuator is not expected to be very large or heavy. For reference, the Vega 3rd stage TVC electromechanical actuator, which can provide more than $1000 \mathrm{~W}$ mechanical power has a mass of $17 \mathrm{~kg}$. The thrust of the Vega rocket engine is over $300 \mathrm{kN}$, compared to the NTR engine in this study with thrust of $111 \mathrm{kN}$. The exact configuration of the actuator depends on how and where the actuators are mounted. Actuators that are located close to the engine centerline would need to provide high force over a short distance, resulting in a short, fat actuator. The same torque and range can be provided by an actuator that is located further from the engine centerline, resulting in a longer, more slender actuator, with a higher slew rate.

It is likely that launch loads on an NTR engine and TVC actuators will exceed loads during the in-space mission. Some sort of engine restraint may be necessary during launch, as was assumed for some NERVA missions.

\subsection{Conclusion}

Vehicles for future NTR mission are likely to have steady state engine thrust imbalances and CG offsets that make it desirable to gimbal engine thrust, reducing the vehicle attitude control demands on RCS. The range of necessary engine gimbaling to trim the vehicle is dependent on the combination of expected thrust offsets, engine mounting misalignments and CG offsets.

Thrust vector control can also be useful for transient scenarios such as engine start and off-nominal engine shutdown. These cases drive gimbal rate and gimbal power requirements. Simulation result showed gimbal range requirements up to $2.4^{\circ}$ and rates up to $1.85^{\circ}$ per second, though most cases had modest gimbal rates of $0.5^{\circ}$ per second or less. Mechanical power requirements are low, based on the assumptions used in these simulations. Further definition of quantities such as gimbal friction and engine thrust offset will improve confidence in actuator power requirements.

The use of a 6 degree-of-freedom simulation model enabled the assessment of a wide variety of flight scenarios for evaluation of TVC requirements. The rigid body model showed the basic controllability of vehicles using TVC, for various combinations of thrust levels and vehicle mass moment of inertias. Some investigations with propellant slosh effects indicated little impact on TVC requirements, but controller parameters are definitely important. A key design requirement is that the attitude controller bandwidth remain below slosh frequencies (on the order of $0.1 \mathrm{~Hz}$ ) and vehicle flex mode frequencies (ideally $1 \mathrm{~Hz}$ and higher). Future studies will look further at the impacts of vehicle slosh, flexibility and the effects of real actuators and real attitude sensors.

\section{References}

1. Borowski, S.K., McCurdy, D.R., and Packard, T.W., "Modular Growth NTR Space Transportation System for Future NASA Human Lunar, NEA and Mars Exploration Missions," AIAA-2012-5144, Sept. 2012.

2. Finseth, J.L., "Overview of Rover Engine Tests, Final Report," NASA CR-184270, 1991.

3. Koeing, D.R., "Experience gained From the Space Nuclear Rocket Programs (Rover/NERVA)," Los Alamos National Laboratory, Report LA-10062-H, Los Alamos, NM, May 1986.

4. Lockheed Missiles and Space Co., "The NERVA-RIFT Thrust Vector Control/Mechanical/Shielding Interface Review Meeting," 1963, available from National Technical Information Service, Accession Number NSP-63-87.

5. Dodge, F.T., "The New Dynamic Behavior of Liquids in Moving Containers," Southwest Research Institute, San Antonio, Texas, 2000, (update of NASA SP-106 edited by Abramson, N.). 
6. Altseimer, J.H., Mader, G.F., Stewart, J.J., "Operating Characteristics and Requirements for the NERVA Flight Engine," Journal of Spacecraft, Vol. 8, No. 7., 1971, pp. 766-773; also AIAA Paper 70-676, July 1970.

7. Gran, K., Rossi, M., Moyer, H.G., and Austin, F., "Control of Large Space Structures," Grumman Aerospace Corporation, NASA CR-161369, 1979.

8. Carnevale, C., Resta, P.D., "Vega Electromechanical Thrust Vector Control Development," AIAA-2007-5812, July 2007. 



\begin{tabular}{|c|c|c|}
\hline \multicolumn{2}{|c|}{ REPORT DOCUMENTATION PAGE } & $\begin{array}{l}\text { Form Approved } \\
\text { OMB No. 0704-0188 }\end{array}$ \\
\hline \multicolumn{3}{|c|}{ 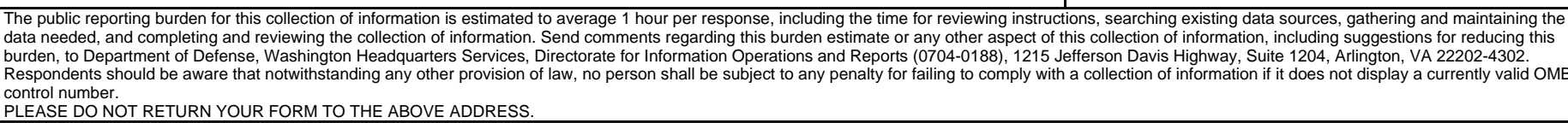 } \\
\hline $\begin{array}{l}\text { 1. REPORT DATE (DD-MM-YYYY) } \\
01-10-2013\end{array}$ & $\begin{array}{l}\text { 2. REPORT TYPE } \\
\text { Technical Memorandum }\end{array}$ & 3. DATES COVERED (From - To) \\
\hline \multirow{3}{*}{\multicolumn{2}{|c|}{$\begin{array}{l}\text { 4. TITLE AND SUBTITLE } \\
\text { Thrust Vector Control for Nuclear Thermal Rockets }\end{array}$}} & 5a. CONTRACT NUMBER \\
\hline & & 5b. GRANT NUMBER \\
\hline & & 5c. PROGRAM ELEMENT NUMBER \\
\hline \multirow{3}{*}{\multicolumn{2}{|c|}{$\begin{array}{l}\text { 6. AUTHOR(S) } \\
\text { Ensworth, Clinton, B.F. }\end{array}$}} & 5d. PROJECT NUMBER \\
\hline & & 5e. TASK NUMBER \\
\hline & & $\begin{array}{l}\text { 5f. WORK UNIT NUMBER } \\
\text { WBS 279585.04.01.22 }\end{array}$ \\
\hline \multicolumn{2}{|c|}{$\begin{array}{l}\text { 7. PERFORMING ORGANIZATION NAME(S) AND ADDRESS(ES) } \\
\text { National Aeronautics and Space Administration } \\
\text { John H. Glenn Research Center at Lewis Field } \\
\text { Cleveland, Ohio 44135-3191 }\end{array}$} & $\begin{array}{l}\text { 8. PERFORMING ORGANIZATION } \\
\text { REPORT NUMBER } \\
\text { E-18782 }\end{array}$ \\
\hline \multirow{2}{*}{\multicolumn{2}{|c|}{$\begin{array}{l}\text { 9. SPONSORING/MONITORING AGENCY NAME(S) AND ADDRESS(ES) } \\
\text { National Aeronautics and Space Administration } \\
\text { Washington, DC 20546-0001 }\end{array}$}} & $\begin{array}{l}\text { 10. SPONSORING/MONITOR'S } \\
\text { ACRONYM(S) } \\
\text { NASA }\end{array}$ \\
\hline & & $\begin{array}{l}\text { 11. SPONSORING/MONITORING } \\
\text { REPORT NUMBER } \\
\text { NASA/TM-2013-218087 }\end{array}$ \\
\hline \multicolumn{3}{|c|}{$\begin{array}{l}\text { 12. DISTRIBUTION/AVAILABILITY STATEMENT } \\
\text { Unclassified-Unlimited } \\
\text { Subject Category: } 18 \\
\text { Available electronically at http://www.sti.nasa.gov } \\
\text { This publication is available from the NASA Center for AeroSpace Information, 443-757-5802 }\end{array}$} \\
\hline
\end{tabular}

\section{ABSTRACT}

Future space missions may use Nuclear Thermal Rocket (NTR) stages for human and cargo missions to Mars and other destinations. The vehicles are likely to require engine thrust vector control (TVC) to maintain desired flight trajectories. This paper explores requirements and concepts for TVC systems for representative NTR missions. Requirements for TVC systems were derived using 6 degree-of-freedom models of NTR vehicles. Various flight scenarios were evaluated to determine vehicle attitude control needs and to determine the applicability of TVC. Outputs from the models yielded key characteristics including engine gimbal angles, gimbal rates and gimbal actuator power. Additional factors such as engine thrust variability and engine thrust alignment errors were examined for impacts to gimbal requirements. Various technologies are surveyed for TVC systems for the NTR applications. A key factor in technology selection is the unique radiation environment present in NTR stages. Other considerations including mission duration and thermal environments influence the selection of optimal TVC technologies. Candidate technologies are compared to see which technologies, or combinations of technologies best fit the requirements for selected NTR missions. Representative TVC systems are proposed and key properties such as mass and power requirements are defined. The outputs from this effort can be used to refine NTR system sizing models, providing higher fidelity definition for TVC systems for future studies.

15. SUBJECT TERMS

Nuclear Thermal Rocket (NTR); Thrust Vector Control (TVC); Spacecraft; Attitude control; Simulation

\begin{tabular}{|c|c|c|c|c|c|}
\hline \multicolumn{3}{|c|}{ 16. SECURITY CLASSIFICATION OF: } & \multirow{2}{*}{$\begin{array}{l}\text { 17. LIMITATION OF } \\
\text { ABSTRACT } \\
\text { UU }\end{array}$} & \multirow{2}{*}{$\begin{array}{l}\text { 18. NUMBER } \\
\text { OF } \\
\text { PAGES } \\
32\end{array}$} & \multirow{2}{*}{$\begin{array}{l}\text { 19a. NAME OF RESPONSIBLE PERSON } \\
\text { STI Help Desk (email:help@sti.nasa.gov) } \\
\text { 19b. TELEPHONE NUMBER (include area code) } \\
\text { 443-757-5802 }\end{array}$} \\
\hline $\begin{array}{l}\text { a. REPORT } \\
\text { U }\end{array}$ & $\begin{array}{l}\text { b. ABSTRACT } \\
\text { U }\end{array}$ & $\begin{array}{l}\text { c. THIS } \\
\text { PAGE } \\
\text { U }\end{array}$ & & & \\
\hline
\end{tabular}



